\title{
Ultrasound angiology reference standards of fetal cerebroplacental flow in normal Egyptian gestation: statistical analysis of one thousand observations
}

\author{
Ashraf Anas Zytoon ${ }^{*}$ (D), Hayam Abd Elmonsif Abd Ellatif and Doha Nazeh Yousef
}

\begin{abstract}
Background: Doppler velocity assessment is the most frequently used method in clinical practice to identify fetal well-being, as it is considered as a non-invasive estimation of the fetus and feto-placental circulation. The aim of the current study is to establish longitudinal reference ranges for MCA and UA Doppler velocities, systolic-todiastolic (S/D) ratio, resistive index (RI) and PI, and cerebroplacental ratio. The current study was a multicentric longitudinal study of 428 singleton pregnancies and 1284 observations. Doppler ultrasound, middle cerebral artery (MCA) and umbilical artery (UA) peaked velocities, and pulsatility index (PI) were evaluated three times throughout a single session over gestational age range of 13-40 weeks.

Results: Based on 1284 observations, new longitudinal reference ranges for fetal middle cerebral peak systolic velocity (PSV), PI, RI, and S/D; reference ranges for umbilical artery PSV, PI, RI, and S/D; and reference ranges for cerebroplacental ratio PSV, PI, RI, and S/D were established. MCA PI, RI, PSV, and S/D curves are of parabolic pattern, and UA PI, RI, and S/D curves are decreased by age while UA PSV curve is of parabolic pattern; furthermore, cerebroplacental ratio (CPR) PI, RI, and S/D curves increased by age while CPR PSV curve decreased then increased by age. The reference ranges were at nearly variant from earlier studies and close to other studies.

Conclusions: In the Doppler data combining both umbilical and cerebral velocimetry, MCA/UA ratio incorporates information not only on placental station but also on fetal response; it is possibly more beneficial in anticipating perinatal outcome.
\end{abstract}

Keywords: Middle cerebral artery (MCA), Umbilical artery (UA), Cerebroplacental ratio (CPR), Doppler, Feto-placental circulation

\section{Background}

Calculation of the blood flow to the fetal brain has developed as an indispensable part of the assessment of high-risk pregnancies. Recent studies on the role of CPR Doppler demonstrated a strong association with lower gestational age (GA) at delivery, lower birth weight (BW) and 5-min Apgar score, and higher incidence of small for gestational age (SGA) along with an increased frequency of need for neonatal intensive care unit (NICU) [1-3].

\footnotetext{
* Correspondence: ashradio@gmail.com

Radiodiagnosis Department, Faculty of Medicine, Menoufia University, Shebeen El-Kom, Egypt
}

\section{Springer Open}

The fetal cerebral blood flow evaluation has become an essential part of the assessment of high-risk pregnancies. The middle cerebral artery (MCA) Doppler findings are incorporated regularly into the management of fetuses at risk of developing placental insufficiency and fetal anemia [4]. It has been a routine practice to use UA pulsatility index (PI) and MCA PI to distinguish between constitutionally small babies and growth-restricted ones, and it has been found to be supportive in deciding the best time, place, and mode of delivery [5].

Middle cerebral artery (MCA) is an honest mirror for fetal cardiovascular adoptions to hypoxia or blood flow readjustment [6]. Hence, diminished PI has been 
considered a compensatory action to secure the fetal brain in the setting of intrauterine growth restriction (IUGR) [7]. Abnormal CPR was related to lower birth weight (BW) [8].

The association between abnormal MCA blood flow velocity and fetal compromise has been previously demonstrated using peak systolic velocity [9].

It is believed that the cerebroplacental ratio (CPR) measures the cardiac output redistribution from representative cerebral and feto-placental vessels and is evolving as a serious criterion in the evaluation of fetal wellbeing in fetal growth retardation $[4,10]$.

These findings indicate that there is a mutual relation between the hemoglobin concentration and the velocity of cerebral blood flow [11].

There is evidence from the previous studies that the Doppler parameters differ with race and ethnicity [12-14].
It is therefore recommended that the data from regional population should be available to be used as reference in clinical practice. The purpose of this study was therefore to establish longitudinal reference ranges for MCA and UA Doppler velocities, S/D ratio, RI and PI, and the cerebroplacental ratio, and to offer standards for calculating confident reference intervals appropriate for discrete sequential measurements in normal Egyptian gestation.

\section{Methods}

This current study was a longitudinal multicentric study of 428 singleton pregnancies (1284 observations). The patients were informed of the examination and gave a verbal informed consent to perform the examination.

Doppler ultrasound, umbilical artery (UA) and middle cerebral artery (MCA) flow velocities, and pulsatility index (PI) were observed three times throughout a single

Table 1 Patient demographics

\begin{tabular}{|c|c|c|c|c|c|c|}
\hline & Number of pregnant women & Maternal age & FHR & EFW & Placental grade & Placental thickness $(\mathrm{cm})$ \\
\hline $13 \mathrm{~W}$ & 10 & $18-40$ & $154-177$ & $42-64$ & I & $1.0-2.0$ \\
\hline $14 \mathrm{~W}$ & 10 & $25-37$ & $153-164$ & $64-85$ & $|-| \mid$ & $1.5-3.0$ \\
\hline $15 \mathrm{~W}$ & 10 & $23-40$ & $143-165$ & $96-127$ & $|-| \mid$ & $1.9-2.9$ \\
\hline $16 \mathrm{~W}$ & 10 & $24-42$ & $143-162$ & $121-174$ & $|-| \mid$ & $1.7-3.1$ \\
\hline $17 \mathrm{~W}$ & 10 & $18-35$ & 144-191 & 135-193 & $|-| \mid$ & $2.0-3.0$ \\
\hline $18 \mathrm{~W}$ & 10 & $22-31$ & $146-159$ & $225-235$ & $|-| \mid$ & $2.5-3.1$ \\
\hline $19 W$ & 10 & $24-34$ & $148-158$ & $263-408$ & $|-| \mid$ & $2.0-3.5$ \\
\hline $20 \mathrm{~W}$ & 11 & $16-35$ & $123-157$ & $294-362$ & $|-| \mid$ & $1.7-3.1$ \\
\hline $21 \mathrm{~W}$ & 10 & $25-38$ & $146-154$ & $412-556$ & $\|$ & $2.2-3.1$ \\
\hline $22 \mathrm{~W}$ & 10 & $24-28$ & $152-161$ & $453-549$ & $\|-\| \|$ & $2.5-3.4$ \\
\hline $23 \mathrm{~W}$ & 10 & $23-34$ & 139-161 & 533-617 & ॥ & $2.2-4.0$ \\
\hline $24 \mathrm{~W}$ & 10 & $20-33$ & 149-158 & $631-741$ & ॥ & $2.0-4.0$ \\
\hline $25 \mathrm{~W}$ & 9 & $25-29$ & $157-164$ & $765-810$ & $\|$ & $3.2-3.5$ \\
\hline $26 \mathrm{~W}$ & 10 & $20-32$ & $141-153$ & 563-1069 & $\|-|I|$ & $2.5-3.7$ \\
\hline $27 \mathrm{~W}$ & 10 & $24-37$ & $146-160$ & $631-1284$ & $\|$ & $2.4-4.0$ \\
\hline $28 \mathrm{~W}$ & 10 & $22-34$ & 138-155 & $1051-1509$ & $\|-1\|$ & $2.2-4.4$ \\
\hline $29 \mathrm{~W}$ & 10 & $26-33$ & 137-165 & 1307-1449 & $\|-|I|$ & $3.0-4.2$ \\
\hline $30 \mathrm{~W}$ & 10 & $24-41$ & $142-157$ & $1538-1604$ & $\|-1\|$ & $2.9-3.9$ \\
\hline $31 \mathrm{~W}$ & 10 & $27-30$ & $136-161$ & $1617-1828$ & $\|-\| \|$ & $3.0-3.9$ \\
\hline $32 \mathrm{~W}$ & 9 & $20-33$ & $141-161$ & $1551-2464$ & $\|-\| \|$ & $3.0-4.5$ \\
\hline $33 \mathrm{~W}$ & 10 & $23-35$ & 149-151 & $2052-2201$ & III & $2.6-3.5$ \\
\hline $34 \mathrm{~W}$ & 15 & $20-27$ & $138-160$ & $2052-2706$ & $\|-\| \|$ & $2.8-5.2$ \\
\hline $35 \mathrm{~W}$ & 22 & $23-30$ & $120-140$ & 2298-2810 & $\|-|| \mid$ & $3.1-4.2$ \\
\hline $36 \mathrm{~W}$ & 32 & $17-32$ & $123-144$ & $2341-2700$ & III & $2.9-3.9$ \\
\hline $37 \mathrm{~W}$ & 49 & $20-35$ & $120-150$ & $2582-3203$ & III & $2.8-4.0$ \\
\hline $38 \mathrm{~W}$ & 49 & 19-36 & $124-147$ & $2893-3320$ & III & $3.0-4.1$ \\
\hline $39 W$ & 30 & $22-34$ & $125-148$ & $2730-3429$ & III & $3.1-4.3$ \\
\hline $40 \mathrm{~W}$ & 22 & $23-37$ & $130-149$ & 2930-3481 & III & $3.3-4.5$ \\
\hline
\end{tabular}


Table 2 Gestational age-defined reference ranges for MCA PSV/ UA PSV ratio

\begin{tabular}{|c|c|c|c|c|c|c|c|c|}
\hline \multirow{2}{*}{$\begin{array}{l}\text { GA } \\
\text { (weeks) }\end{array}$} & \multicolumn{8}{|c|}{ Centiles of MCA PSV/UA PSV ratio } \\
\hline & $1 s t$ & 2.5th & 5 th & 10th & 90th & 95th & 97.5th & 99th \\
\hline 13.0 & 0.26 & 0.31 & 0.37 & 0.43 & 1.32 & 1.53 & 1.74 & 2.01 \\
\hline 13.5 & 0.26 & 0.31 & 0.36 & 0.43 & 1.30 & 1.50 & 1.70 & 1.96 \\
\hline 14.0 & 0.26 & 0.31 & 0.36 & 0.43 & 1.27 & 1.47 & 1.66 & 1.91 \\
\hline 14.5 & 0.27 & 0.31 & 0.36 & 0.43 & 1.25 & 1.44 & 1.63 & 1.87 \\
\hline 5.0 & 0.27 & 0.31 & 0.36 & 0.43 & 1.23 & 1.41 & 1.59 & 1.83 \\
\hline 5.5 & 0.27 & 0.32 & 0.36 & 0.43 & 1.21 & 1.39 & 1.57 & 1.80 \\
\hline 5.0 & 0.27 & 0.32 & 0.36 & 0.43 & 1.20 & 1.37 & 1.54 & 1.77 \\
\hline 16.5 & 0.27 & 0.32 & 0.36 & 0.43 & 1.18 & 1.35 & 1.52 & 1.74 \\
\hline 7.0 & 0.27 & 0.32 & 0.37 & 0.43 & 1.17 & 1.34 & 1.50 & 1.72 \\
\hline 17.5 & 0.27 & 0.32 & 0.37 & 0.43 & 1.16 & 1.33 & 1.49 & 1.70 \\
\hline 18.0 & 0.28 & 0.32 & 0.37 & 0.43 & 1.15 & 1.32 & 1.47 & 1.68 \\
\hline 18.5 & 0.28 & 0.32 & 0.37 & 0.43 & 1.15 & 1.31 & 1.46 & 1.67 \\
\hline 19.0 & 0.28 & 0.33 & 0.37 & 0.43 & 1.14 & 1.30 & 1.46 & 1.65 \\
\hline .5 & 0.28 & 0.33 & 0.37 & 0.43 & 1.14 & 1.30 & 1.45 & 1.65 \\
\hline 0.0 & 0.28 & 0.33 & 0.38 & 0.43 & 1.14 & 1.29 & 1.45 & 1.64 \\
\hline .5 & 0.29 & 0.33 & 0.38 & 0.44 & 1.14 & 1.29 & 1.44 & 1.64 \\
\hline .0 & 0.29 & 0.34 & 0.38 & 0.44 & 1.14 & 1.29 & 1.44 & 1.64 \\
\hline .5 & 0.29 & 0.34 & 0.38 & 0.44 & 1.14 & 1.30 & 1.45 & 1.64 \\
\hline .0 & 0.29 & 0.34 & 0.39 & 0.45 & 1.15 & 1.30 & 1.45 & 1.64 \\
\hline 2.5 & 0.30 & 0.34 & 0.39 & 0.45 & 1.15 & 1.31 & 1.45 & 1.65 \\
\hline 23.0 & 0.30 & 0.35 & 0.39 & 0.45 & 16 & 1.31 & 1. & 1.65 \\
\hline .5 & 0.30 & 0.35 & 0.39 & 0.46 & 1.16 & 1.32 & 1.47 & 1.66 \\
\hline .0 & 0.30 & 0.35 & 0.40 & 0.46 & 1.17 & 1.33 & 1.48 & 1.68 \\
\hline 5 & 0.31 & 0.35 & 0.40 & 0.46 & 1.18 & 1.34 & 1.49 & 1.69 \\
\hline .0 & 0.31 & 0.36 & 0.40 & 0.47 & 1.19 & 1.35 & 1.51 & 1.71 \\
\hline .5 & 0.31 & 0.36 & 0.41 & 0.47 & 1.21 & 1.37 & 1.52 & 1.73 \\
\hline .0 & 0.31 & 0.36 & 0.41 & 0.47 & 1.22 & 1.38 & 1.54 & 1.75 \\
\hline .5 & 0.31 & 0.36 & 0.41 & 0.48 & 1.23 & 1.40 & 1.56 & 1.77 \\
\hline 27.0 & 0.32 & 0.37 & 0.42 & 0.48 & 1.25 & 1.42 & 1.58 & 1.79 \\
\hline .5 & 0.32 & 0.37 & 0.42 & 0.48 & 1.26 & 1.44 & 1.60 & 1.82 \\
\hline 3.0 & 0.32 & 0.37 & 0.42 & 0.49 & 1.28 & 1.46 & 1.63 & 1.85 \\
\hline 3.5 & 0.32 & 0.37 & 0.42 & 0.49 & 1.30 & 1.48 & 1.65 & 1.88 \\
\hline 290 & 0.32 & 0.37 & 0.43 & 0.49 & 1.32 & 1.50 & 1.68 & 1.91 \\
\hline .5 & 0.32 & 0.37 & 0.43 & 0.50 & 1.34 & 1.53 & 1.71 & 1.94 \\
\hline 30.0 & 0.32 & 0.38 & 0.43 & 0.50 & 1.36 & 1.55 & 1.74 & 1.98 \\
\hline SU.J & 0.32 & 0.38 & 0.43 & 0.50 & 1.38 & 1.58 & 1.77 & 2.02 \\
\hline 0 & 0.32 & 0.38 & 0.43 & 0.50 & 1.40 & 1.60 & 1.80 & 2.06 \\
\hline 政 & 0.32 & 0.38 & 0.43 & 0.51 & 1.42 & 1.63 & 1.84 & 2.10 \\
\hline .0 & 0.32 & 0.38 & 0.43 & 0.51 & 1.45 & 1.66 & 1.87 & 2.14 \\
\hline & 0.32 & 0.38 & 0.43 & 0.51 & 1.47 & 1.69 & 1.91 & 2.19 \\
\hline 33.0 & 0.32 & 0.38 & 0.43 & 0.51 & 1.49 & 1.72 & 1.95 & 2.24 \\
\hline & 0.32 & 0.38 & 0.43 & 0.51 & 1.52 & 1.76 & 1.99 & 2.29 \\
\hline
\end{tabular}

Table 2 Gestational age-defined reference ranges for MCA PSV/ UA PSV ratio (Continued)

\begin{tabular}{lllllllll}
\hline GA & \multicolumn{1}{l}{ Centiles of MCA PSV/UA PSV ratio } \\
\cline { 2 - 10 } & 1st & 2.5th & 5 th & 10th & 90th & 95th & 97.5 th & 99 th \\
\hline 34.0 & 0.31 & 0.37 & 0.43 & 0.51 & 1.55 & 1.79 & 2.03 & 2.34 \\
34.5 & 0.31 & 0.37 & 0.43 & 0.51 & 1.57 & 1.82 & 2.07 & 2.39 \\
35.0 & 0.31 & 0.37 & 0.43 & 0.51 & 1.60 & 1.86 & 2.11 & 2.45 \\
35.5 & 0.30 & 0.37 & 0.43 & 0.51 & 1.62 & 1.89 & 2.16 & 2.50 \\
36.0 & 0.30 & 0.36 & 0.43 & 0.51 & 1.65 & 1.93 & 2.20 & 2.56 \\
36.5 & 0.30 & 0.36 & 0.42 & 0.51 & 1.68 & 1.97 & 2.25 & 2.62 \\
37.0 & 0.29 & 0.36 & 0.42 & 0.51 & 1.71 & 2.00 & 2.30 & 2.68 \\
37.5 & 0.29 & 0.35 & 0.42 & 0.50 & 1.73 & 2.04 & 2.34 & 2.75 \\
38.0 & 0.28 & 0.35 & 0.41 & 0.50 & 1.76 & 2.08 & 2.39 & 2.81 \\
38.5 & 0.28 & 0.34 & 0.41 & 0.50 & 1.79 & 2.12 & 2.44 & 2.88 \\
39.0 & 0.27 & 0.34 & 0.40 & 0.49 & 1.82 & 2.16 & 2.49 & 2.95 \\
39.5 & 0.26 & 0.33 & 0.39 & 0.49 & 1.84 & 2.19 & 2.55 & 3.02 \\
40.0 & 0.26 & 0.32 & 0.39 & 0.48 & 1.87 & 2.23 & 2.60 & 3.09 \\
\hline
\end{tabular}

Reference ranges for MCA PSV/UA PSV based on 1284 observations show parabolic course which ranges from 0.26 to 1.75 with average 0.79 at 2 nd trimester, and ranges from 0.31 to 3.09 with average 1.00 at 3rd trimester

session over gestational age range of 13-40 weeks. Polynomial regression lines for the 1st, 2.5th, 5th, 10th, 90th, 95th, 97.5th, and 99th percentiles were calculated for the peak systolic velocity (PSV), systolic-to-diastolic ratio (S/ $\mathrm{D}$ ratio), resistive index (RI), PI, and CPR. Standards for estimating precise references were established.

The study population of 428 women (1284 observations) "as each artery examined at least 3 times" was recruited from the normal pregnancy population to a prospective analytic study of the cerebral and umbilical arterial circulation. Gestational age was assessed by ultrasound head biometry (BPD and $\mathrm{HC}$ ), AC, and FL. The results of the MCA, UA, and cerebroplacental ratio were presented in that study. The current study was approved by the institutional ethical committee.

The assortment of patients to that study was created on predefined criteria.

\section{Inclusion criteria}

Pregnant females who met the following criteria were involved in this study: normal pregnancy, exact gestational age based on the last menstruation date adapted with ultrasound parameters, gestational age between 13 and 40 weeks, normal fetal growth (between 10th and 90th percentiles of the growth chart), and normal Doppler pattern of MCA and UA arteries (Table 1).

\section{Exclusion criteria}

The exclusion criteria were as follows: multiple pregnancies, fetal abnormalities, history of hypertension, diabetes mellitus, oligohydramnios (amniotic fluid index <5), 
biophysical profile $<6$, autoimmune conditions, preeclampsia, abnormal vaginal bleeding, hydrops fetalis and consumption of hormonal contraceptive agents, IUGR, large for gestational age, and presence of any general chronic disease. None of the fetuses was at risk of developing anemia.

\section{Technique}

Each woman was examined with three measurements per session. Fetal weight, FHR, placental grade and thickness, and maternal age were noted.

Doppler ultrasound measurements were recorded using a $2-5 \mathrm{MHz}$ transabdominal transducer (Philips HD9, Philips HD11, GE LOGIC P3, and GE LOGIC P5). The filter was set to $70 \mathrm{~Hz}$. The MCA was imaged using color mapping in an axial view of the brain. The Doppler beam was focused along the MCA, and the sample size (median, $3 \mathrm{~mm}$; mean, $3.5 \mathrm{~mm}$; range, $1-7 \mathrm{~mm}$ ) was placed where the MCA arises from the circle of Willis.

Once the MCA in the close field could not be depicted, the MCA of the contralateral side was used. The recordings were attained in the absence of fetus breathing or movements. The Doppler waveforms were traced automatically and manually, and the PSV, S/D ratio, RI, and PI were determined and calculated.

The waveforms from the UA were obtained in a freemoving segment of the umbilical cord using an equivalent technique in alignment with the direction of the vessel. The angle of estimation of the UA should be zero as probable and less than $60^{\circ}$. The PSV, S/D ratio, RI, and PI were determined and were entered into the statistics, and the cerebroplacental ratios were calculated (Table 2, Fig. 1).

The number of pregnant females required to achieve the percentiles based on the collected data has been considered to be not less than 10 participants per gestational week.

\section{Statistical methods}

Multilevel modeling was used in order to calculate mean percentiles for the MCA Doppler PSV, S/D ratio, RI, and PI according to gestational age. To achieve normal distribution of outcome variables, the Box-Cox power transformation was used. Fractional polynomial regression models [15] were fitted to the data in order to construct mean curves for PSV, S/D ratio, RI, and PI according to gestational age. Multilevel model was used, where the first level was the variance between measurements within the same fetus and the second was the variance between the participating women. The choice of fixed and random components in the models was based on gain in likelihood. Statistical analysis was proficient using MedCalc $\odot$ version 15 (MedCalc $\odot$ Software, Ostend, Belgium).

The methodology used to model the reference intervals for Doppler parameters on gestational age is based on the methods described by Altman and Chitty [16], Wright and Royston [17], and Altman and Chitty [18].

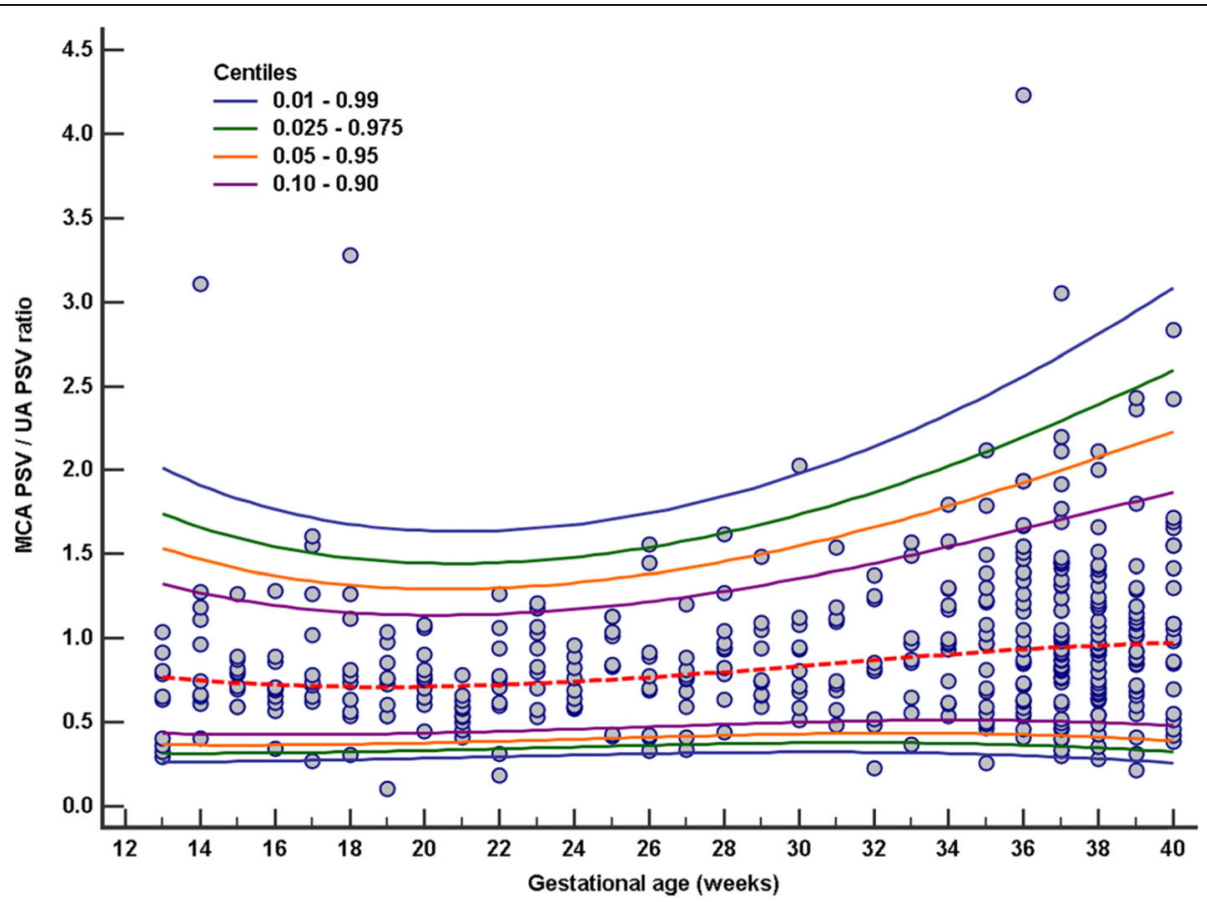

Fig. 1 PSV MCA/UA. Scattered diagram of gestational age individual measurement and calculated reference ranges for MCA PSV/UA PSV in normal pregnancies (1284 observations) with 1st-99th percentiles (blue lines) and 50th percentiles (red dashed line) 
Table 3 Gestational age-defined reference ranges for MCA S/D to UA S/D ratio

\begin{tabular}{|c|c|c|c|c|c|c|c|c|}
\hline \multirow{2}{*}{$\begin{array}{l}\text { GA } \\
\text { (weeks) }\end{array}$} & \multicolumn{8}{|c|}{ Centiles of MCA S/D to UA S/D ratio } \\
\hline & $1 s t$ & 2.5th & 5 th & 10th & 90th & 95th & 97.5th & 99 th \\
\hline 13.0 & 0.29 & 0.33 & 0.38 & 0.44 & 1.12 & 1.27 & 1.41 & 1.60 \\
\hline 13.5 & 0.30 & 0.35 & 0.40 & 0.46 & 1.18 & 1.33 & 1.48 & 1.68 \\
\hline 14.0 & 0.32 & 0.37 & 0.42 & 0.48 & 1.23 & 1.40 & 1.56 & 1.76 \\
\hline 14.5 & 0.34 & 0.39 & 0.44 & 0.51 & 1.29 & 1.46 & 1.63 & 1.84 \\
\hline 15.0 & 0.36 & 0.41 & 0.47 & 0.53 & 1.35 & 1.53 & 1.70 & 1.92 \\
\hline 15.5 & 0.37 & 0.43 & 0.49 & 0.56 & 1.41 & 1.59 & 1.77 & 2.00 \\
\hline 16.0 & 0.39 & 0.45 & 0.51 & 0.58 & 1.46 & 1.66 & 1.84 & 2.08 \\
\hline 16.5 & 0.41 & 0.47 & 0.53 & 0.61 & 1.52 & 1.72 & 1.91 & 2.16 \\
\hline 17.0 & 0.42 & 0.49 & 0.55 & 0.63 & 1.58 & 1.78 & 1.98 & 2.23 \\
\hline 17.5 & 0.44 & 0.51 & 0.57 & 0.66 & 1.63 & 1.84 & 2.05 & 2.31 \\
\hline 18.0 & 0.46 & 0.53 & 0.59 & 0.68 & 1.69 & 1.91 & 2.11 & 2.38 \\
\hline 18.5 & 0.47 & 0.54 & 0.61 & 0.70 & 1.74 & 1.97 & 2. & 2.46 \\
\hline 19.0 & 0.49 & 0.56 & 0.63 & 0.73 & 1.79 & 2.02 & 2.25 & 2.53 \\
\hline 19.5 & 0.50 & 0.58 & 0.65 & 0.75 & 1.84 & 2.08 & 2.31 & 2.60 \\
\hline 20.0 & 0.52 & 0.60 & 0.67 & 0.77 & 1.89 & 2.14 & 2.37 & 2.67 \\
\hline .5 & 0.53 & 0.61 & 0.69 & 0.79 & 1.94 & 2.19 & 2. & 2.74 \\
\hline 21.0 & 0.55 & 0.63 & 0.71 & 0.81 & 1.99 & 2.24 & 2.49 & 2.80 \\
\hline 21.5 & 0.56 & 0.64 & 0.72 & 0.83 & 2.03 & 2.29 & 2.54 & 2.86 \\
\hline 2.0 & 0.57 & 0.66 & 0.74 & 0.85 & 2.08 & 2.34 & 2.60 & 2.93 \\
\hline 22.5 & 0.58 & 0.67 & 0.75 & 0.86 & 2.12 & 2.39 & 2.65 & 2.98 \\
\hline 23.0 & 0.59 & 0.68 & 0.77 & 0.88 & 2.16 & 2.44 & 2. & 04 \\
\hline 23.5 & 0.60 & 0.69 & 0.78 & 0.89 & 2.20 & 2.48 & 2.75 & 3.09 \\
\hline 24.0 & 0.61 & 0.71 & 0.79 & 0.91 & 2.23 & 2.52 & 2.79 & 3.15 \\
\hline 4.5 & 0.62 & 0.72 & 0.81 & 0.92 & 2.27 & 2.56 & 2.84 & 3.20 \\
\hline 25.0 & 0.63 & 0.73 & 0.82 & 0.94 & 2.30 & 2.60 & 2.88 & 3.24 \\
\hline 5.5 & 0.64 & 0.73 & 0.83 & 0.95 & 2.33 & 2 & 2 & 29 \\
\hline 26.0 & 0.65 & 0.74 & 0.84 & 0.96 & 2.36 & 2.66 & 2.96 & 3.33 \\
\hline 26.5 & 0.65 & 0.75 & 0.84 & 0.97 & 2.39 & 2.70 & 2.99 & 3.37 \\
\hline 27.0 & 0.66 & 0.76 & 0.85 & 0.98 & 2.41 & 2.72 & 3.02 & 3.41 \\
\hline 27.5 & 0.66 & 0.76 & 0.86 & 0.98 & 2.44 & 2.75 & 3.05 & 3.44 \\
\hline 3.0 & 0.67 & 0.77 & 0.86 & 0.99 & 2.46 & 2.78 & 3.08 & 3.47 \\
\hline 28.5 & 0.67 & 0.77 & 0.87 & 1.00 & 2.48 & 2.80 & 3.11 & 3.50 \\
\hline 0 & 0.67 & 0.77 & 0.87 & 1.00 & 2.50 & 2.82 & 3.13 & 3.53 \\
\hline 29.5 & 0.67 & 0.78 & 0.88 & 1.01 & 2.51 & 2.84 & 3.15 & 3.56 \\
\hline 30.0 & 0.68 & 0.78 & 0.88 & 1.01 & 2.53 & 2.86 & 3.17 & 3.58 \\
\hline 30.5 & 0.68 & 0.78 & 0.88 & 1.01 & 2.54 & 2.87 & 3.19 & 3.60 \\
\hline 31.0 & 0.68 & 0.78 & 0.88 & 1.02 & 2.55 & 2.89 & 3.21 & 3.62 \\
\hline 31.5 & 0.68 & 0.78 & 0.89 & 1.02 & 2.56 & 2.90 & 3.22 & 3.64 \\
\hline 32.0 & 0.68 & 0.78 & 0.89 & 1.02 & 2.57 & 2.91 & 3.24 & 3.66 \\
\hline 32.5 & 0.68 & 0.78 & 0.88 & 1.02 & 2.58 & 2.92 & 3.25 & 3.67 \\
\hline .0 & 0.68 & 0.78 & 0.88 & 1.02 & 2.59 & 2.93 & 3.26 & 3.69 \\
\hline & 0.67 & 0.78 & 0.88 & 1.02 & 2.59 & 2.94 & 3.27 & 3.70 \\
\hline
\end{tabular}

Table 3 Gestational age-defined reference ranges for MCA S/D to UA S/D ratio (Continued)

\begin{tabular}{|c|c|c|c|c|c|c|c|c|}
\hline \multirow{2}{*}{$\begin{array}{l}\text { GA } \\
\text { (weeks) }\end{array}$} & \multicolumn{8}{|c|}{ Centiles of MCA S/D to UA S/D ratio } \\
\hline & 1st & 2.5th & 5 th & 10th & 90th & 95th & 97.5th & 99th \\
\hline 1.0 & 0.67 & 0.78 & 0.88 & 1.01 & 2.60 & 2.94 & 3.28 & 71 \\
\hline 34.5 & 0.67 & 0.78 & 0.88 & 1.01 & 2.60 & 2.95 & 3.28 & 3.72 \\
\hline 5.0 & 0.67 & 0.77 & 0.88 & 1.01 & 2.60 & 2.95 & 3.29 & 3.73 \\
\hline 35.5 & 0.66 & 0.77 & 0.87 & 1.01 & 2.60 & 2.96 & 3.30 & 3.73 \\
\hline 5.0 & 0.66 & 0.77 & 0.87 & 1.00 & 2.60 & 2.96 & 3.30 & 3.74 \\
\hline 36.5 & 0.66 & 0.76 & 0.87 & 1.00 & 2.61 & 2.96 & 3.30 & 3.75 \\
\hline 7.0 & 0.65 & 0.76 & 0.86 & 1.00 & 2.61 & 2.96 & S. & 3.75 \\
\hline 7.5 & 0.65 & 0.75 & 0.86 & 0.99 & 2.60 & 2.96 & 3.31 & 3.76 \\
\hline 3.0 & 0.64 & 0.75 & 0.85 & 0.99 & 2.60 & 2.96 & 3.31 & S \\
\hline 38.5 & 0.64 & 0.75 & 0.85 & 0.98 & 2.60 & 2.96 & 3.31 & 3.76 \\
\hline 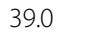 & 0.64 & 0.74 & 0.84 & 0.98 & 2.60 & 2.96 & 3.31 & 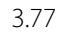 \\
\hline 39.5 & 0.63 & 0.74 & 0.84 & 0.97 & 2.60 & 2.96 & 3.32 & 3.77 \\
\hline 40.0 & 0.63 & 0.73 & 0.83 & 0.97 & 2.60 & 2.96 & 3.32 & S \\
\hline
\end{tabular}

Reference ranges for MCA S/D ratio to UA S/D ratio based on 1284 observations show parabolic course which ranges from 0.29 to 3.33 with average 1.30 at 2 nd trimester, and ranges from 0.65 to 3.78 with average 1.81 at 3rd trimester

The statistical technique includes the following phases: If the distribution of the estimations (the variable for which to create a reference interval) shows skewness at diverse stages of gestational age, the estimations are analyzed employing a Box-Cox power transformation. The transformed measurements are modeled on gestational age using weighted polynomial regression (Altman and Chitty $[18,19])$. This regression model gives the mean of the (transformed) measurements as a function of gestational age: mean (gestational age).

The residuals of this regression model are calculated. The absolute residuals, multiplied by $\sqrt{\pi / 2}$ are modeled on gestational age using weighted polynomial regression (Altman [13]). This second regression model gives the standard deviation of the (transformed) measurements as a function of gestational age: SD (gestational age) (Table 3, Fig. 2).

For every gestational age in the observed range, the reference interval is calculated by taking mean (gestational age) $\pm z \times$ SD (gestational age). For a $95 \%$ reference interval, $z=1.96$. The resulting values are then back changed to their original scale. Based on $1284 \mathrm{ob}-$ servations (428 singleton pregnancies), new longitudinal reference ranges for fetal middle cerebral PSV, S/D ratio, $\mathrm{RI}$, and PI provided terms for calculating conditional reference intervals (anticipating expected 95\% confidence intervals based on a prior estimations), and consistently for the cerebroplacental ratio were presented.

The reference angles were at some variance and compared with those of previous cross-sectional studies. The 


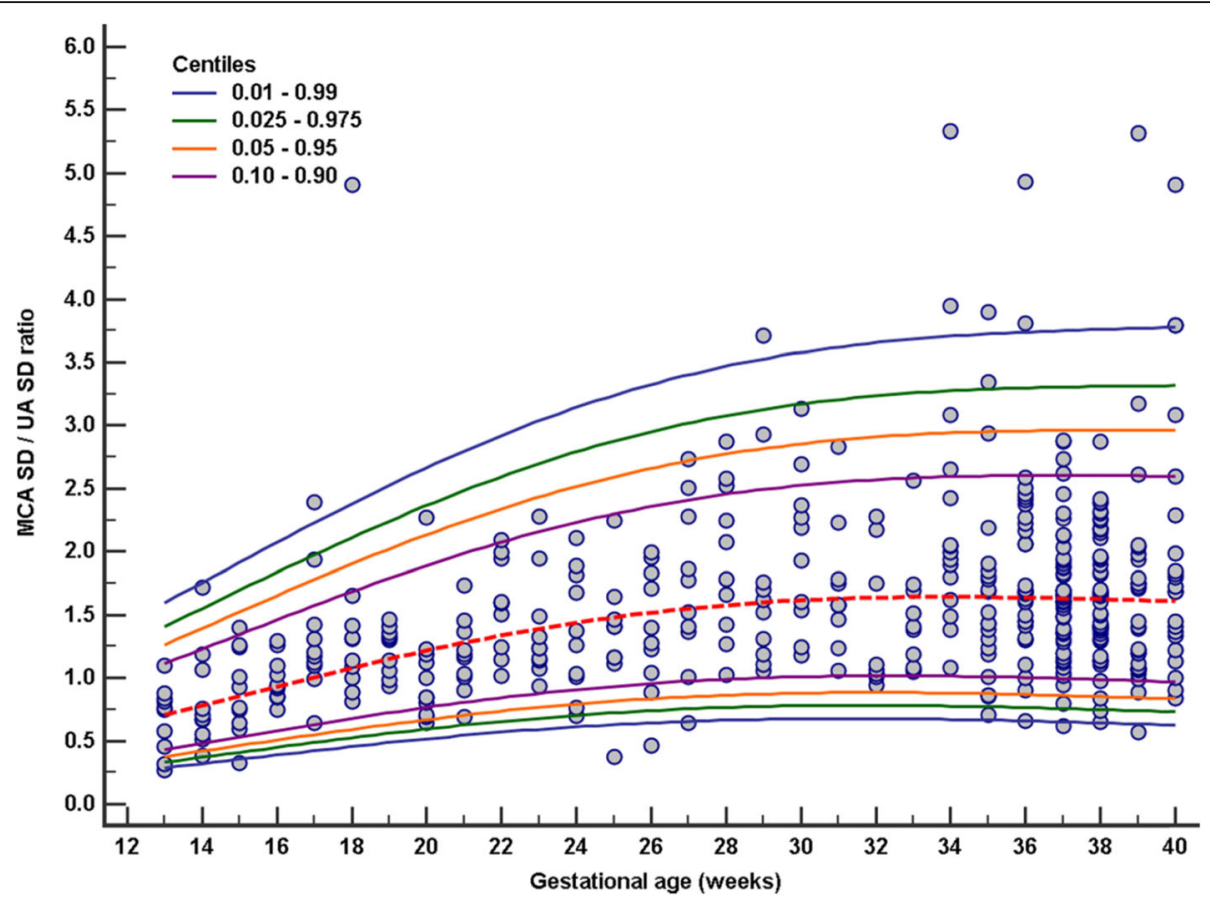

Fig. 2 S/D ratio MCA/UA. Scattered diagram of gestational age individual measurement and calculated reference ranges for MCA S/D ratio to UA S/D ratio in normal pregnancies (1284 observations) with 1st-99th percentiles (blue lines) and 50th percentiles (red dashed line)

consistent gestational age-defined reference values for the 1st, 2.5th, 5th, 10th, 90th, 95th, 97.5th, and 99th percentiles of MCA, UA and CPR PSV, S/D ratio, RI, and PI are presented in the tables (Fig. 6).

\section{Results}

In the current study, 1284 observations of the MCA and UA velocity as well as MCA to UA velocity ratio observations were obtained.

The UA PI declined linearly from mean 1.18 at 21 weeks to 0.81 at 39 weeks. MCA velocities were amplified throughout the second half of pregnancy. The PSV increased not as much during the last 10 weeks of pregnancy. The cerebroplacental percentage enlarged from mean 1.07 at 21 weeks of pregnancy to a peak 1.26 at 33 weeks.

Characteristics of the study population are presented in Table 1 where maternal age ranges from 16 to 42 years old with median age 30 years old, FHR ranges from 120 to $165 \mathrm{bpm}$ with median $142 \mathrm{bpm}$, EFW ranges from 42 to $3481 \mathrm{~g}$ with median weight $1761.5 \mathrm{~g}$, placental grade ranges from grade I to III, and placental thickness was from 1.0 to $4.2 \mathrm{~cm}$. In the present study, the number of pregnant females examined at each week was at least 9 with a maximum of 49 females (Table 4, Fig. 3).

\section{Discussion}

In the current study, MCA values demonstrated a parabolic pattern, but the UA values showed a linear decrease with increasing gestational age. In their findings,
Umarwal and Kumar [20] demonstrated increase in MCA Doppler values till 33-35 weeks and then a decline till 40 weeks of gestation. The MCA Doppler displayed a parabolic curve and was equivalent to Bahlmann et al.'s study [21].

Some studies displayed that MCA blood flow abnormalities were associated with hypoxia adverse perinatal outcome and suboptimal neurodevelopment; thus, its appraisal by pulsed Doppler is standard for antenatal care of pregnancy at risk such as those supposed to be affected by growth restriction, multiple gestation, hypertension during pregnancy, parvovirus B19 infection fetal anemia, Rh immunization, fetal hydrops, suspected fetal anomalies, and large chorioangioma [22-24].

Modern work has recommended that the proportion of MCA PI to UA PI, the cerebroplacental ratio (CPR), is a self-reliant indicator of fetal compromise [25], Cesarean section [26], and poor perinatal outcome [5, 27-29]. Subsequently, UA and MCA Doppler indices and CPR are now utilized to adjust the planning of antepartum surveillance and, in few proportions of patients, to judge the date of delivery for the compromised fetus [25].

MCA PSV expects and assists in treatment of fetal compromise. The relationship between abnormal MCA flow velocity and fetal anemia has been formerly established by means of the peak systolic velocity. The PSV in the middle cerebral artery decays when the fetal hematocrit upsurges. The monitoring of fetus at risk typically necessitates consecutive Doppler assessment, including the MCA [30-32]. 
Table 4 Gestational age-defined reference ranges for MCA RI/ UA RI ratio

\begin{tabular}{|c|c|c|c|c|c|c|c|c|}
\hline \multirow{2}{*}{$\begin{array}{l}\text { GA } \\
\text { (weeks) }\end{array}$} & \multicolumn{8}{|c|}{ Centiles of MCA PI/UA RI ratio } \\
\hline & $1 s t$ & 2.5th & 5 th & 10th & 90th & 95th & 97.5th & 99th \\
\hline 0 & 0.53 & 0 & 0.63 & 59 & 99 & 1.14 & 19 & 1.25 \\
\hline 13.5 & 0.55 & 0.61 & 0.65 & 0.71 & 1.10 & 1.15 & 1.20 & 1.26 \\
\hline 14.0 & 0.58 & 0.63 & 0.67 & 0.73 & 1.10 & 1.16 & 1.21 & 1.26 \\
\hline 14.5 & 0.60 & 0.65 & 0.69 & 0.74 & 1.11 & 1.17 & 1.21 & 1.27 \\
\hline 5.0 & 0.62 & 0.67 & 0.71 & 0.76 & 1.12 & 1.17 & 1.22 & 1.27 \\
\hline 15.5 & 0.64 & 0.69 & 0.73 & 0.78 & 1.13 & 1.18 & 1.23 & 1.28 \\
\hline 16.0 & 0.66 & 0.71 & 0.75 & 0.80 & 1.14 & 1.19 & 1.23 & 1.28 \\
\hline 6.5 & 0.68 & 0.73 & 0.77 & 0.81 & 1.15 & 1.20 & 1.24 & 1.29 \\
\hline 17.0 & 0.70 & 0.74 & 0.78 & 0.83 & 1.16 & 1.21 & 1.25 & 1.30 \\
\hline 7.5 & 0.71 & 0.76 & 0.80 & 0.84 & 1.17 & 1.22 & 1.26 & 1.31 \\
\hline 18.0 & 0.73 & 0.77 & 0.81 & 0.86 & 1.18 & 1.23 & 1.27 & 1.31 \\
\hline 18.5 & 0.75 & 0.79 & 0.83 & 0.87 & 1.19 & 1.24 & 1.28 & 1.32 \\
\hline 9.0 & 0.76 & 0.80 & 0.84 & 0.89 & 1.20 & 1.25 & 1.28 & 1.33 \\
\hline 19.5 & 0.77 & 0.82 & 0.86 & 0.90 & 1.21 & 1.25 & 1.29 & 1.34 \\
\hline 0.0 & 0.79 & 0.83 & 0.87 & 0.91 & 1.22 & 1.26 & 1.30 & 1.35 \\
\hline .5 & 0.80 & 0.84 & 0.88 & 0.92 & 1.23 & 1.28 & 1.31 & 1.36 \\
\hline .0 & 0.81 & 0.85 & 0.89 & 0.93 & 1.24 & 1.29 & 1.32 & 1.37 \\
\hline 1.5 & 0.82 & 0.86 & 0.90 & 0.94 & 1.25 & 1.30 & 1.33 & 1.38 \\
\hline 2.0 & 0.83 & 0.87 & 0.91 & 0.95 & 1.26 & 1.31 & 1. & 1.39 \\
\hline .5 & 0.84 & 0.88 & 0.92 & 0.96 & 1.27 & 1.32 & 1.36 & 1.40 \\
\hline 23.0 & 0.85 & 0.89 & 0.93 & 0.97 & 1.28 & 1.33 & 1.37 & 1.41 \\
\hline 5 & 36 & 0.90 & 4 & 8 & 1.30 & 4 & 1 & 1.43 \\
\hline 4.0 & 0.86 & 0.91 & 0.94 & 0.99 & 1.31 & 1.35 & 1.39 & 1.44 \\
\hline 1.5 & 0.87 & 0.91 & 0.95 & 1.00 & 132 & 1.36 & 1.4 & 1.45 \\
\hline 25.0 & 0.87 & 0.92 & 0.96 & 1.00 & 1.33 & 1.38 & 1.42 & 1.46 \\
\hline .5 & 0.88 & 0.92 & 0.96 & 1.01 & 1.34 & 1.39 & 1.43 & 1.48 \\
\hline .0 & 0.88 & 0.93 & 0.97 & 1.01 & 1.35 & 1.40 & 1 & 49 \\
\hline 6.5 & 0.88 & 0.93 & 0.97 & 1.02 & 1.36 & 1.41 & 1.46 & 1.51 \\
\hline 0 & 0.88 & 0.93 & 0.97 & 1.02 & 1.38 & 1.43 & 1.47 & 1.5 \\
\hline 27.5 & 0.88 & 0.93 & 0.98 & 1.03 & 1.39 & 1.44 & 1.49 & 1.54 \\
\hline 3.0 & 0.88 & 0.93 & 0.98 & 1.03 & 1.40 & 1.45 & 1.50 & 1.55 \\
\hline 28.5 & 0.88 & 0.93 & 0.98 & 1.03 & 1.41 & 1.47 & 1.52 & 1.57 \\
\hline 29.0 & 0.88 & 0.93 & 0.98 & 1.03 & 1.43 & 1.48 & 1.53 & 1.59 \\
\hline . & 0.87 & 0.93 & 0.98 & 1.04 & 1.44 & 1.50 & 1.55 & 1.60 \\
\hline 30.0 & 0.87 & 0.93 & 0.98 & 1.04 & 1.45 & 1.51 & 1.56 & 1.62 \\
\hline 5 & 0.87 & 0.93 & 0.98 & 1.04 & 1.46 & 1.52 & 1.58 & 1.64 \\
\hline 31.0 & 0.86 & 0.92 & 0.97 & 1.04 & 1.48 & 1.54 & 1.59 & 1.66 \\
\hline 31.5 & 0.85 & 0.92 & 0.97 & 1.03 & 1.49 & 1.55 & 1.61 & 1.68 \\
\hline .0 & 0.85 & 0.91 & 0.97 & 1.03 & 1.50 & 1.57 & 1.63 & 1.70 \\
\hline 32.5 & 0.84 & 0.90 & 0.96 & 1.03 & 1.52 & 1.58 & 1.65 & 1.72 \\
\hline 0 & 0.83 & 0.90 & 0.96 & 1.03 & 1.53 & 1.60 & 1.66 & 1.74 \\
\hline 3.5 & 0.82 & 0.89 & 0.95 & 1.02 & 1.54 & 1.62 & 1.68 & 1.76 \\
\hline
\end{tabular}

Table 4 Gestational age-defined reference ranges for MCA RI/ UA RI ratio (Continued)

\begin{tabular}{lllllllll}
\hline GA & \multicolumn{7}{l}{ Centiles of MCA PI/UA RI ratio } \\
\cline { 2 - 10 } & 1st & 2.5th & 5 th & 10th & 90th & 95th & 97.5 th & 99th \\
\hline 34.0 & 0.81 & 0.88 & 0.95 & 1.02 & 1.56 & 1.63 & 1.70 & 1.78 \\
34.5 & 0.80 & 0.87 & 0.94 & 1.02 & 1.57 & 1.65 & 1.72 & 1.80 \\
35.0 & 0.78 & 0.86 & 0.93 & 1.01 & 1.58 & 1.67 & 1.74 & 1.82 \\
35.5 & 0.77 & 0.85 & 0.92 & 1.00 & 1.60 & 1.68 & 1.76 & 1.84 \\
36.0 & 0.76 & 0.84 & 0.91 & 1.00 & 1.61 & 1.70 & 1.78 & 1.87 \\
36.5 & 0.74 & 0.83 & 0.90 & 0.99 & 1.62 & 1.72 & 1.80 & 1.89 \\
37.0 & 0.72 & 0.81 & 0.89 & 0.98 & 1.64 & 1.73 & 1.82 & 1.91 \\
37.5 & 0.71 & 0.80 & 0.88 & 0.97 & 1.65 & 1.75 & 1.84 & 1.94 \\
38.0 & 0.69 & 0.79 & 0.87 & 0.97 & 1.67 & 1.77 & 1.86 & 1.96 \\
38.5 & 0.67 & 0.77 & 0.86 & 0.96 & 1.68 & 1.79 & 1.88 & 1.99 \\
39.0 & 0.65 & 0.75 & 0.84 & 0.95 & 1.70 & 1.81 & 1.90 & 2.01 \\
39.5 & 0.63 & 0.74 & 0.83 & 0.94 & 1.71 & 1.82 & 1.92 & 2.04 \\
40.0 & 0.61 & 0.72 & 0.81 & 0.92 & 1.73 & 1.84 & 1.94 & 2.06 \\
\hline
\end{tabular}

Reference ranges for MCA RI/UA RI based on 1284 observations show parabolic course which ranges from 0.53 to 1.49 with average 1.06 at 2 nd trimester, and ranges from 0.88 to 2.06 with average 1.28 at 3rd trimester

The multiples of median (MOM) derived in Umarwal and Kumar's [20] study and in the study by Akolekar et al. [10] were similar (5th, 50th, and 95th centile of MCA PI was $0.7,1.0$, and 1.23 , respectively, compared to $0.8,1.0$, and 1.3 in the present study).

The use of such standards depends on suitable reference ranges; however, while several cross-sectional reference ranges are now in use [31], these are less suitable for serial observations because the appropriate reference ranges for consecutive measurements necessitate longitudinal statistics [15] (Fig. 7).

According to Dunn et al. [33], there is a strong association between CPR and the adverse obstetric and perinatal outcomes. The CPR can depict the redistribution of blood flow by two probable mechanisms. "Forced centralization" that may be experienced with increased placental blood flow resistance as well as diminishing cerebral blood flow resistance due to "brain sparing" can both affect the CPR [34, 35].

The CPR ratio has increasingly been incorporated in the surveillance of the fetus at risk by repeating the assessment at intervals. For serial assessments, the reference ranges should be based on studies with a longitudinal design $[15,36]$.

In the present study, longitudinal reference ranges with percentile charts were constructed for the cerebroplacental ratio through serial measurements for the PSV, RI, S/D ratio, and PI of the UA and MCA in relation to the gestational age. In real terms, this means that the predictable 50th percentile and equivalent ranges can be adjusted according to the earlier reflection. The reference ranges 


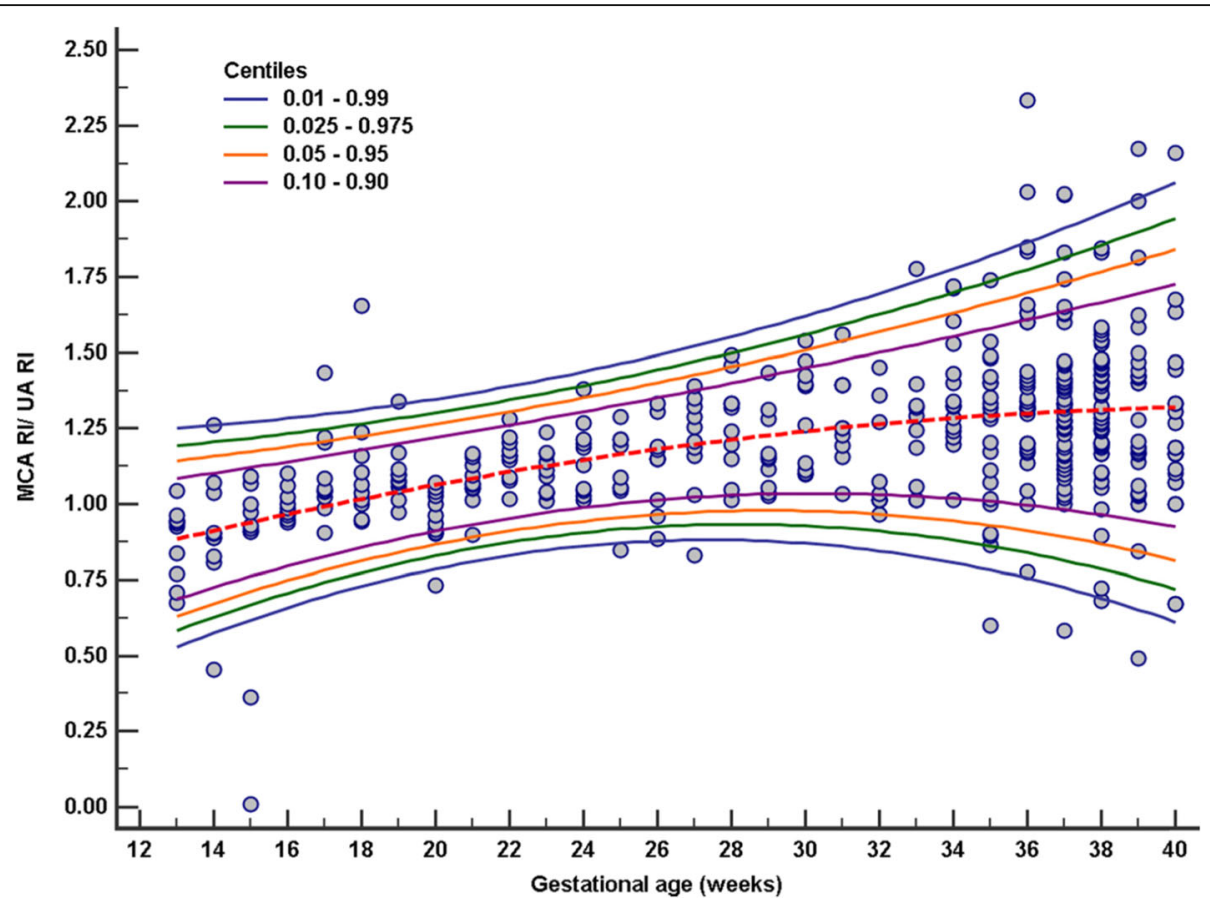

Fig. 3 RI MCA/UA. Scattered diagram of gestational age individual measurement and calculated reference ranges for MCA RI/UA RI in normal pregnancies (1284 observations) with 1st-99th percentiles (blue lines) and 50th percentiles (red dashed line)

recognized for the MCA differ slightly from those of cross-sectional studies. In comparison of the current reference MCA PSV values with those published by Tarzamni et al. [37] (at 20 weeks $20 \pm 12.23$, at 30 weeks $46.42 \pm$ 11.16 , and at 40 weeks $54.42 \pm 23.48$ ), and comparing with Ebbing et al. [38] (at 21 weeks 24.09, at 30 weeks 41.98, and at 39 weeks 55.7), the present study results were 43.17 at 20 weeks, 44.4 at 21 weeks, 47.79 at 30 weeks, 40.55 at 39 weeks, and 39.35 at 40 weeks (Table 5, Fig. 4).

The current study results demonstrate that the increase in velocity is blunted after 36 weeks of gestation and probably reflects a physiological reduction of vascular impedance.

MCA-PSV median slope has been demonstrated as an excellent tool for identifying fetal anemia and, therefore, Doppler ultrasonography could be applied in monitoring pregnancies at risk for fetal anemia [39]. The study by Kurmanavicius et al. [32] on MCA PSV had insufficient explanations for the last weeks of pregnancy, while Bahlmann et al. [31] had few notes in the early weeks and excluded fetuses with abnormal biometric parameters.

The fluctuation of velocities and indices has been displayed to be greater and the PI higher in the distal segment in comparison with the proximal third of the MCA. Consequently, procedure standardization was done to obtain the best accurate observations, so the estimated Doppler velocities were registered at the origin of the vessel at the circle of Willis, and an insonation allied accurately along the vessel was achieved.
In contrast of this study baseline value MCA PI curve with those issued by Ebbing et al. [40], it was determined that reference limits during 19 to 41 weeks found that reference curve for the PI was characterized by a parabolic pattern (21 weeks, 1.6; 30 week, 2.2; 39 weeks, 1.5), in comparison with the current reference MCA PI curve with those published by Tarzamni et al. [37] that result to 20 weeks, 1.72 ; 28 weeks, 2.05; and 40 weeks, 1.23 and in comparison with the current reference MCA PI curve with those published by Parra-Cordero et al. [40] that result to 21 weeks, 2.01; 30 weeks, 2.21; and 40 weeks, 1.14; the difference with this result is due to small sample (number of measurement is 160), while in the current results (at 20 weeks, 1.54; at 21 weeks, 1.56; at 28 weeks, 1.57; at 30 weeks, 1.57; at 39 weeks, 1.37; and at 40 weeks, 1.34), it was determined that reference limits during 24 to 40 weeks were lower about $0.01-0.09$ for the current estimations.

Bahlmann et al. [31] found that reference curve for the RI was represented by a parabolic pattern (at 18 weeks, 0.68 ; at 28 weeks, 0.8 ; and at 42 weeks, 0.61 ), and the result published by Kurmanavicius et al. [32] was at 24 weeks, 0.87 ; at 30 weeks, 0.9 ; and at 40 weeks, 0.76 , while the existing results were at 18 weeks, 0.76 ; at 24 weeks, 0.79 ; at 28 weeks, 0.8 ; at 30 weeks, 0.77 ; and at 40 weeks, 0.67 .

The conclusion from the current study results was in close relation with Bahlmann et al.'s [31] findings, Rujiwetpongstorn et al. [41], and Parra-Cordero et al.'s [40] nomograms for MCA RI during 11-20 weeks which 
Table 5 Gestational age-defined reference ranges for MCA PI/ UA PI ratio

\begin{tabular}{|c|c|c|c|c|c|c|c|c|}
\hline \multirow{2}{*}{$\begin{array}{l}\text { GA } \\
\text { (weeks) }\end{array}$} & \multicolumn{8}{|c|}{ Centiles of MCA/UA PI } \\
\hline & $1 \mathrm{st}$ & 2.5th & 5 th & 10th & 90th & 95th & 97.5th & 99th \\
\hline 13.0 & 0.40 & 0.45 & 0.49 & 0.55 & 1.10 & 1.20 & 1.30 & 1.41 \\
\hline 3.5 & 0.42 & 0.47 & 0.52 & 0.58 & 1.14 & 1.24 & 1.34 & 1.46 \\
\hline 4.0 & 0.44 & 0.50 & 0.54 & 0.60 & 1.18 & 1.29 & 1.39 & 1.51 \\
\hline 14.5 & 0.47 & 0.52 & 0.57 & 0.63 & 1.22 & 1.33 & 1.44 & 1.56 \\
\hline 5.0 & 0.49 & 0.54 & 0.59 & 0.65 & 1.26 & 1.38 & 1.48 & 1.61 \\
\hline 5.5 & 0.51 & 0.56 & 0.62 & 0.68 & 1.31 & 1.42 & 1.53 & 1.66 \\
\hline 6.0 & 0.53 & 0.59 & 0.64 & 0.71 & 1.35 & 1.47 & 1.58 & 1.71 \\
\hline 16.5 & 0.55 & 0.61 & 0.66 & 0.73 & 1.39 & 1.51 & 1.62 & 1.76 \\
\hline 7.0 & 0.57 & 0.63 & 0.68 & 0.75 & 1.43 & 1.55 & 1.67 & 1.81 \\
\hline 7.5 & 0.58 & 0.65 & 0.71 & 0.78 & 1.47 & 1.60 & 1.71 & 1.86 \\
\hline 18.0 & 0.60 & 0.67 & 0.73 & 0.80 & 1.51 & 1.64 & 1.76 & 1.91 \\
\hline 3.5 & 0.62 & 0.69 & 0.75 & 0.82 & 1.55 & 1.68 & 1.80 & 1.96 \\
\hline 19.0 & 0.64 & 0.70 & 0.77 & 0.84 & 1.59 & 1.72 & 1.85 & 2.01 \\
\hline 19.5 & 0.65 & 0.72 & 0.78 & 0.86 & 1.62 & 1.76 & 1.89 & 2.05 \\
\hline 20.0 & 0.67 & 0.74 & 0.80 & 0.88 & 1.66 & 1.80 & 1.94 & 2.10 \\
\hline 0.5 & 0.68 & 0.75 & 0.82 & 0.90 & 1.70 & 1.84 & 1.98 & 2.15 \\
\hline 1.0 & 0.69 & 0.77 & 0.83 & 0.92 & 1.73 & 1.88 & 2.02 & 2.19 \\
\hline 21.5 & 0.70 & 0.78 & 0.85 & 0.94 & 1.77 & 1.92 & 2.06 & 2.24 \\
\hline 2.0 & 0.71 & 0.79 & 0.86 & 0.95 & 1.80 & 1.96 & 2.11 & 2.29 \\
\hline 2.5 & 0.72 & 0.80 & 0.87 & 0.96 & 1.84 & 2.00 & 2.15 & 2.33 \\
\hline 23.0 & 0.73 & 0.81 & 0.89 & 0.98 & 1.87 & 2.03 & 2.19 & 2.38 \\
\hline 3.5 & 0.74 & 0.82 & 0.90 & 0.99 & 1.90 & 2.07 & 2.23 & 2.42 \\
\hline 24.0 & 0.74 & 0.83 & 0.90 & 1.00 & 1.93 & 2.11 & 2.27 & 2.47 \\
\hline 24.5 & 0.75 & 0.83 & 0.91 & 1.01 & 1.96 & 2.14 & 2.31 & 2.51 \\
\hline 25.0 & 0.75 & 0.84 & 0.92 & 1.02 & 1.99 & 2.18 & 2.34 & 2.55 \\
\hline 25.5 & 0.76 & 0.84 & 0.93 & 1.03 & 2.02 & 2.21 & 2.38 & 2.60 \\
\hline 26.0 & 0.76 & 0.85 & 0.93 & 1.03 & 2.05 & 2.24 & 2.42 & 2.64 \\
\hline 6.5 & 0.76 & 0.85 & 0.93 & 1.04 & 2.08 & 2.28 & 2.46 & 2.69 \\
\hline 27.0 & 0.76 & 0.85 & 0.94 & 1.04 & 2.11 & 2.31 & 2.50 & 2.73 \\
\hline 27.5 & 0.76 & 0.85 & 0.94 & 1.05 & 2.13 & 2.34 & 2.53 & 2.77 \\
\hline 28.0 & 0.76 & 0.85 & 0.94 & 1.05 & 2.16 & 2.37 & 2.57 & 2.82 \\
\hline 28.5 & 0.75 & 0.85 & 0.94 & 1.05 & 2.18 & 2.40 & 2.61 & 2.86 \\
\hline 29.0 & 0.75 & 0.85 & 0.94 & 1.05 & 2.21 & 2.43 & 2.64 & 2.90 \\
\hline 29.5 & 0.74 & 0.84 & 0.93 & 1.05 & 2.23 & 2.46 & 2.68 & 2.94 \\
\hline 30.0 & 0.74 & 0.84 & 0.93 & 1.05 & 2.26 & 2.49 & 2.71 & 2.99 \\
\hline 30.5 & 0.73 & 0.83 & 0.93 & 1.05 & 2.28 & 2.52 & 2.75 & 3.03 \\
\hline 31.0 & 0.72 & 0.82 & 0.92 & 1.04 & 2.30 & 2.55 & 2.79 & 3.08 \\
\hline 31.5 & 0.72 & 0.82 & 0.92 & 1.04 & 2.33 & 2.58 & 2.82 & 3.12 \\
\hline 32.0 & 0.71 & 0.81 & 0.91 & 1.03 & 2.35 & 2.61 & 2.86 & 3.16 \\
\hline 32.5 & 0.70 & 0.80 & 0.90 & 1.03 & 2.37 & 2.64 & 2.89 & 3.21 \\
\hline 33.0 & 0.69 & 0.79 & 0.89 & 1.02 & 2.39 & 2.67 & 2.93 & 3.26 \\
\hline 33.5 & 0.68 & 0.78 & 0.88 & 1.01 & 2.41 & 2.70 & 2.97 & 3.30 \\
\hline
\end{tabular}

Table 5 Gestational age-defined reference ranges for MCA PI/ UA PI ratio (Continued)

\begin{tabular}{lllllllll}
\hline GA & \multicolumn{1}{l}{ Centiles of MCA/UA PI } \\
\cline { 2 - 9 } & 1st & 2.5 th & 5 th & 10 th & 90 th & 95th & 97.5 th & 99 th \\
\hline 34.0 & 0.67 & 0.77 & 0.87 & 1.01 & 2.44 & 2.73 & 3.00 & 3.35 \\
34.5 & 0.65 & 0.76 & 0.86 & 1.00 & 2.46 & 2.76 & 3.04 & 3.40 \\
35.0 & 0.64 & 0.75 & 0.85 & 0.99 & 2.48 & 2.79 & 3.08 & 3.44 \\
35.5 & 0.63 & 0.74 & 0.84 & 0.98 & 2.50 & 2.82 & 3.12 & 3.49 \\
36.0 & 0.62 & 0.73 & 0.83 & 0.97 & 2.52 & 2.85 & 3.15 & 3.54 \\
36.5 & 0.60 & 0.71 & 0.82 & 0.96 & 2.54 & 2.88 & 3.19 & 3.60 \\
37.0 & 0.59 & 0.70 & 0.81 & 0.95 & 2.56 & 2.91 & 3.23 & 3.65 \\
37.5 & 0.58 & 0.69 & 0.79 & 0.94 & 2.59 & 2.94 & 3.27 & 3.70 \\
38.0 & 0.56 & 0.67 & 0.78 & 0.92 & 2.61 & 2.97 & 3.32 & 3.76 \\
38.5 & 0.55 & 0.66 & 0.77 & 0.91 & 2.63 & 3.00 & 3.36 & 3.81 \\
39.0 & 0.53 & 0.65 & 0.76 & 0.90 & 2.65 & 3.04 & 3.40 & 3.87 \\
39.5 & 0.52 & 0.63 & 0.74 & 0.89 & 2.68 & 3.07 & 3.45 & 3.93 \\
40.0 & 0.51 & 0.62 & 0.73 & 0.87 & 2.70 & 3.10 & 3.49 & 4.00 \\
\hline
\end{tabular}

Reference ranges for MCA PI/UA PI based on 1284 observations show progressive course which ranges from 0.40 to 2.64 with average 1.24 at 2 nd trimester, and ranges from 0.76 to 4.00 with average 1.71 at 3rd trimester

demonstrated diminishing shape without parabolic pattern. In the current study, MCA S/D ratio nomogram had a parabolic pattern similar to that of Tarzamni et al. [37] (at 20 weeks, 5.34; at 30 weeks, 7.13; and at 40 weeks, 3.16), but lower from the existing study results (at 20 weeks, 4.89; at 28 weeks, 4.81; at 30 weeks, 4.95; and at 40 weeks, 3.6) (Fig. 5).

In this way, it has been stated that qualitative changes in UA Doppler, such as the presence, absence, or reversal of end-diastolic velocity, obviously demonstrates an extra hazard of fetal demise [42]. In any case, the affiliation between quantitative changes in UA and MCA Doppler, as measured utilizing PI, and perinatal and long-term results has not been clearly reputable [43, 44].

In comparison of the present reference UA PI curve with those published by Chanprapaph et al. [45], it was demonstrated that a pattern for RI with some difference in ranges was determined (at 21 weeks, 1.27; at 30 weeks, 1.38; and at 40 weeks, 0.9 ).

The current study results regarding PI estimates relatively vary from Parra-Cordero et al.'s [40] results (at 23 weeks, 1.25; at 30 weeks, 1.01; and at 40 weeks, 0.74 ); the difference with this result is due to small sample (number of measurement is 172) while the present study estimations were (at 21 weeks, 0.92 ; at 23 weeks, 1.17; at 30 weeks, 1.03; and at 40 weeks, 0.82 ).

In comparison of the current reference UA RI evaluations with Chanprapaph et al.'s [45] publication, the present study demonstrated a pattern for RI with some difference in ranges which was determined to be close to it (21 weeks, 0.76; 30 weeks, 0.65 ; and 40 weeks, 0.61 ) 


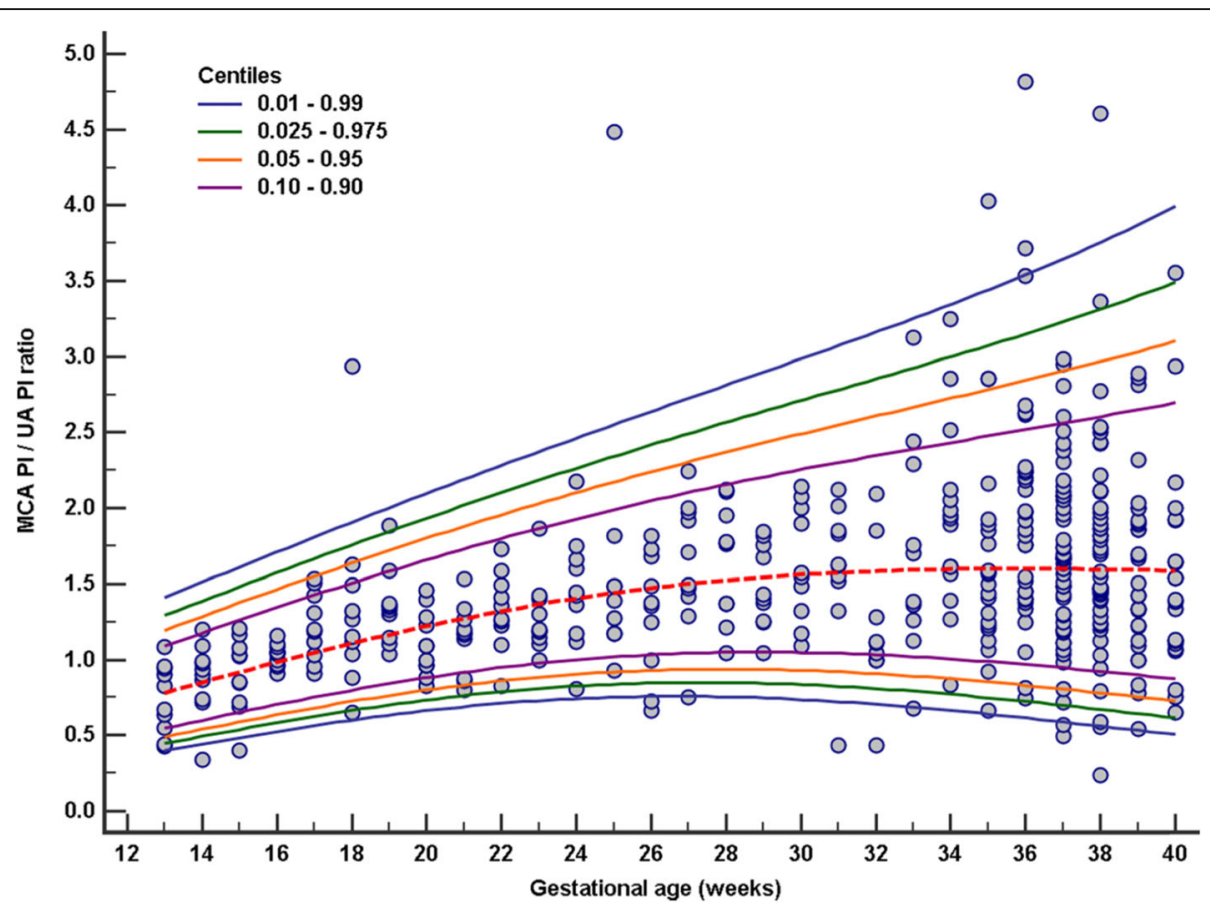

Fig. 4 PI MCA/UA. Scattered diagram of gestational age individual measurement and calculated reference ranges for MCA PI/UA PI in normal pregnancies (1284 observations) with 1st-99th percentiles (blue lines) and 50th percentiles (red dashed line)

and in comparison with those published by Kurmanavicius et al. [32] (at 24 weeks, 0.72; at 30 weeks, 0.66; and at 40 weeks, 0.56 ) while this study's standards were (at 21 weeks, 0.72 ; at 24 weeks, 0.69 ; at 30 weeks, 0.63 ; and at 40 weeks, 0.53 ).

Comparing the current UA S/D ratio curve with Chanprapaph et al.'s [45] results, it demonstrated a pattern for S/D ratio with some difference in ranges (at 21 weeks, 3.56; at 30 weeks, 3.06; at 40 weeks, 2.5), while in the present study (at 21 weeks, 3.95; at 30 weeks, 3.00; at 40 weeks, 2.18), this is due to difference in sample size that was 332 normal singleton pregnant women in reference which was published by Chanprapaph et al. [45].

Because the MCA/UA ratio interrogated data obtained at placental status but also on fetal response, it is actually more beneficial in predicting perinatal conclusion. Doppler data uniting both umbilical and cerebral velocity estimations provide extra information on fetal significances of the placental flow abnormality [46]. Depending on previous calculations, the MCA/UA PI index offers better information in expecting perinatal consequence when compared with umbilical or middle cerebral artery Doppler indices alone [47, 48].

The current CPR PI reference standards were correlated with Baschat et al.'s [47] estimations. A pattern for PI with some difference in ranges was determined (at 20 weeks, 1.37; at 30 weeks, 2.34; at 40 weeks, 1.8 ), while in the present study evaluations (at 20 weeks, 1.27; at 30 weeks, 1.66; at 40 weeks, 1.79 ), this difference may be due to difference in sample size that was 306 normal singleton fetuses in reference published by Baschat et al. [35] (Fig. 6).

Correspondingly, CPR RI reference values correlated with Kurmanavicius et al.'s [32] evaluations (at 24 weeks, 1.23; at 30 weeks, 1.3; and 40 weeks, 1.37), while the existing results are at 24 weeks, 1.15 ; at 30 weeks, 1.25; and at 40 weeks, 1.32 . The number of observations in this existing study is 1435 .

Clarifications for these divergences were due to difference in sample size, sonologist experience and utilization of diverse statistical methods, and curve analysis model. Little observations [47] and unlike location of MCA recording (i.e., distal segment of the vessel [48] instead of the proximal site) may have contributed to the discrepancy between curves. The difference in design and analysis was also expected to cause visible variances [49-51].

Strength points of the present study were that the exact estimation of gestational age is an essential prerequisite for generating any fetal standard [52]. The present study used dating either by LMP corroborated by BPD, HC, AC, and FL. It is cross-sectional study design. It has been observed that the longitudinal studies require more complex statistical calculations and are also liable to have observer bias. In great numbers of observations, each case was examined at least three times and the study was based on a population that had no pregnancy risk nor complications, and surely, the current study reference ranges are reliable and could be applicable in the general population. 


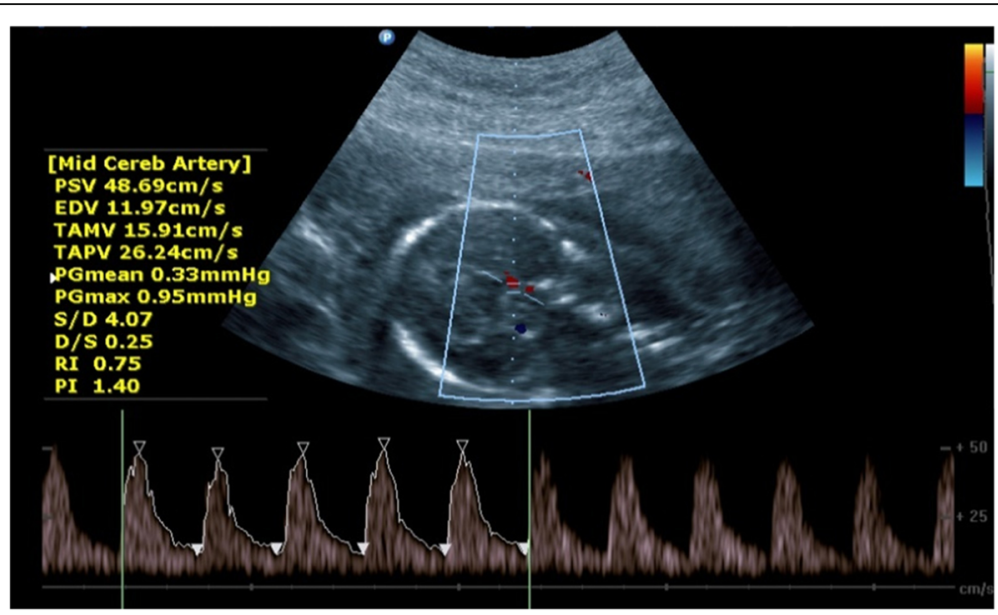

A

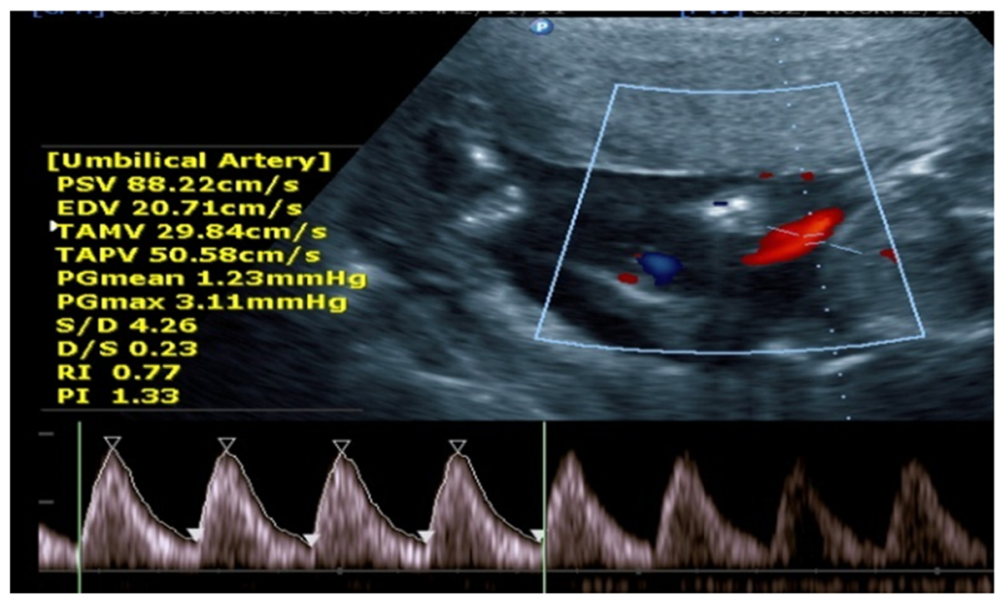

B

Fig. 5 Normal Doppler imaging of MCA and UA at 18 weeks of gestational age in a 31-year-old female mother. FHR, 151 b/m; placenta grade II; and EFW, $202 \mathrm{~g}$. a Doppler US examination of fetal MCA revealed PSV $=48.69, \mathrm{~S} / \mathrm{D}=4.07, \mathrm{RI}=0.75$, and $\mathrm{PI}=1.40$. $\mathbf{b}$ Doppler US examination of maternal UA revealed PSV $=88.22, \mathrm{~S} / \mathrm{D}=4.26, \mathrm{RI}=0.77$, and $\mathrm{PI}=1.33$. CPR Doppler values: $\mathrm{PSV}=0.55, \mathrm{~S} / \mathrm{D}=0.96, \mathrm{RI}=0.97$, and $\mathrm{PI}=1.05$

Both the median and variance ought to be displayed as a function of gestational age in a way that accounts for the expanding variability with gestation and affords smooth centile curves; goodness of fit testing ought to illustrate that these curves depict precisely the structure of the raw information [53]. The present study created scattered diagram curves of gestational age individual measurements and calculated CPR reference ranges for MCA/UA PSV, S/D ratio, RI, and PI in 1284 observations with 1st-99th percentiles, and 50th percentiles clearly demonstrate our tabulated raw data.

Another strength of the study was that any cases with fetal growth restriction or other adverse outcome were excluded. Yet a considerably larger study population would be needed to cover the period of 40-42 weeks of gestation adequately, serial examinations but this seems to be practically challenging as the sonologist are referral observers and also a substantial proportion of the included women in the study delivered before serial estimation follow-up could be ended.

Three quarters of the published references were performed by one sonographer. Multisonographer observations increase external efficacy and data reliability [53]. The current study was performed by 3 radiologists with long term experience 5-25 years in feto-maternal Doppler ultrasonography (Fig. 7).

Furthermore, the current study is not powered to depict a correlation between abnormal CPR and adverse perinatal outcome. Hence, a prospective antepartum fetal care Doppler ultrasound studies are necessary to delineate the role of $\mathrm{CPR}$ as pregnancy outcome predictor for fetal compromise.

\section{Conclusions}

In conclusion, UA velocities giving first impression to fetal compromise and MCA/UA velocities are a powerful 


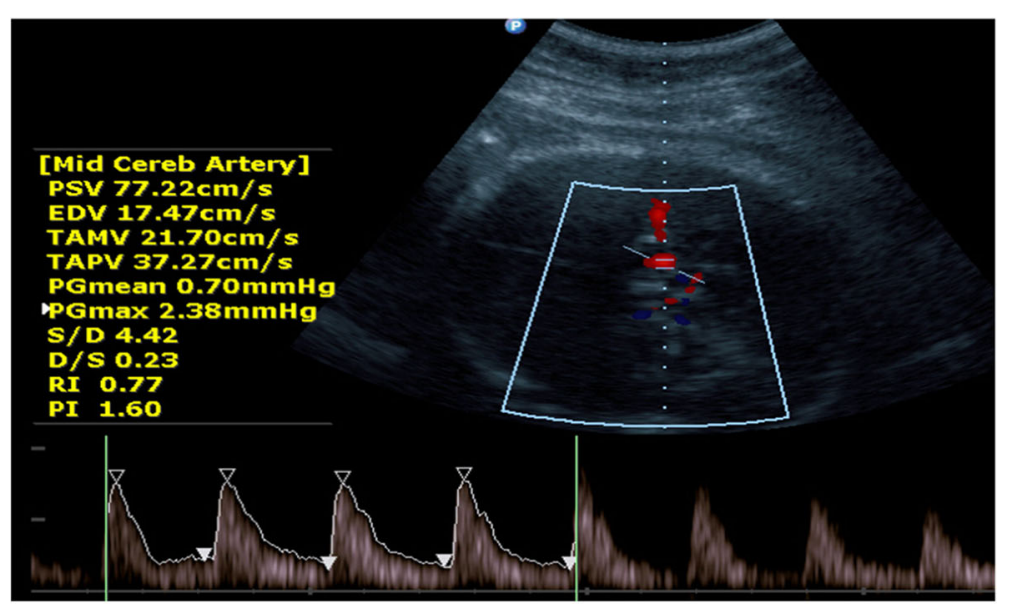

A

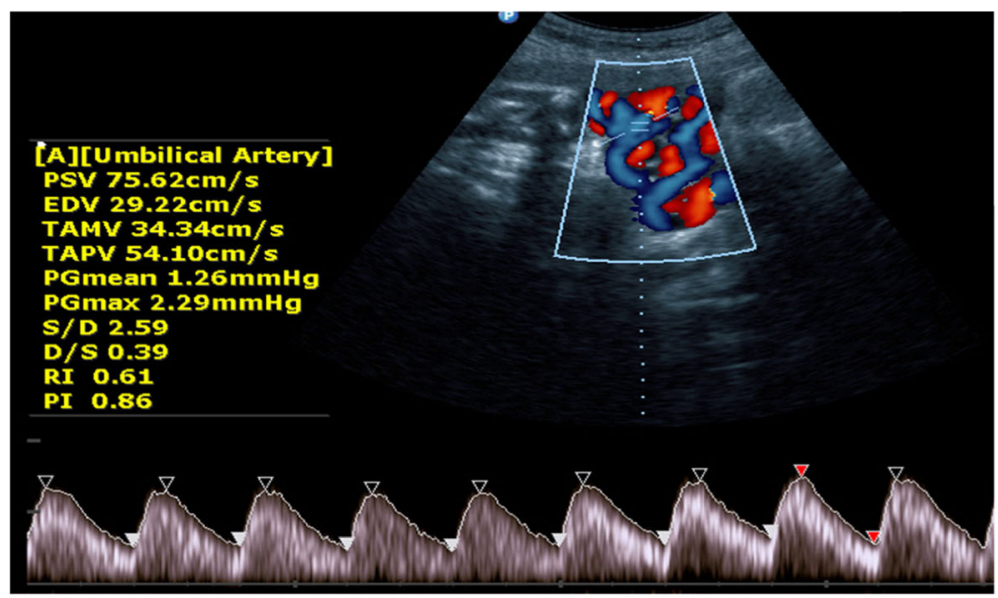

B

Fig. 6 Normal Doppler imaging of MCA and UA at 30 weeks of gestational age in a 24-year-old female mother. FHR, 148 b/m; placenta grade Il; and EFW, $1564 \mathrm{~g}$. a Doppler US examination of fetal MCA revealed PSV $=77.22, \mathrm{~S} / \mathrm{D}=4.42, \mathrm{RI}=0.77$, and $\mathrm{PI}=1.60$. $\mathbf{b}$ Doppler US examination of maternal $\cup A$ revealed $P S V=75.62, S / D=2.59, R I=0.61$, and $P I=0.86 . C P R$ Doppler values: $P S V=1.02, S / D=1.7, R I=1.26$, and $P I=1.86$ 


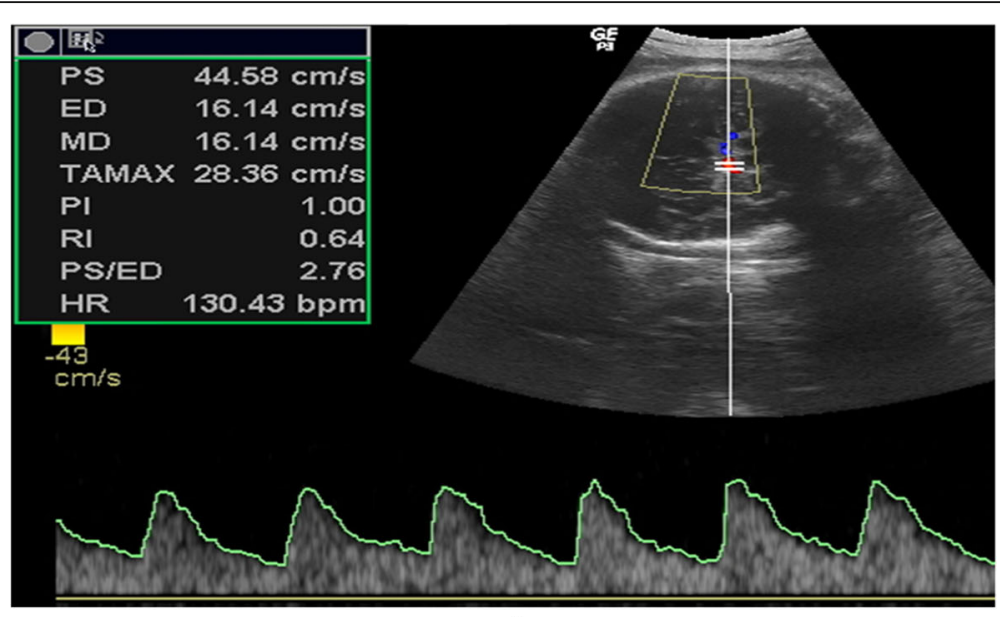

A

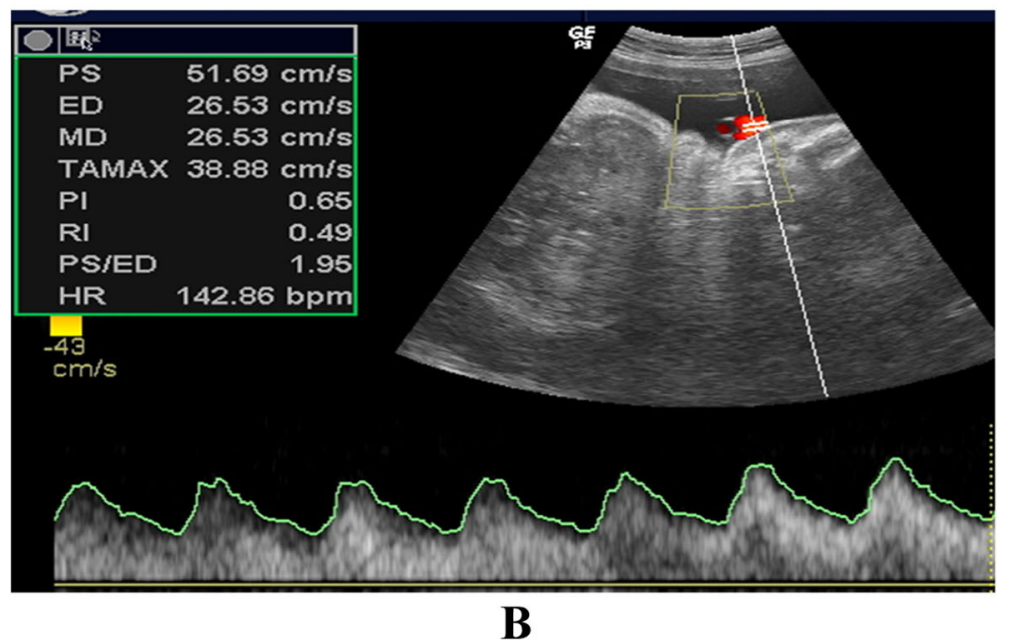

Fig. 7 Normal Doppler imaging of MCA and UA at 40 weeks of gestational age in a 25-year-old female mother. FHR, 136 b/m; placenta grade III; and EFW, $3100 \mathrm{~g}$. a Doppler US examination of fetal MCA revealed PSV $=44.58, \mathrm{~S} / \mathrm{D}=2.76, \mathrm{RI}=0.64$, and $\mathrm{PI}=1.00$. $\mathbf{b}$ Doppler US examination of maternal UA revealed PSV $=51.69, \mathrm{~S} / \mathrm{D}=1.95, \mathrm{RI}=0.49$, and $\mathrm{PI}=0.65 . \mathrm{CPR}$ Doppler values: $\mathrm{PSV}=0.86, \mathrm{~S} / \mathrm{D}=1.41, \mathrm{RI}=1.31$, and $\mathrm{PI}=1.54$ 
tool in fetal assessment. Uniting the Doppler flow analysis of the MCA with the umbilical artery (UA) by a universal cerebroplacental CPR ratio has been recommended as a valuable emerging predictor to improve the accuracy in expecting healthy or poor pregnancy outcome.

\section{Abbreviations}

CPR: Cerebroplacental ratio; IUGR: Intrauterine growth restriction; MCA: Middle cerebral artery; PI: Pulsatility index; PSV: Peak systolic velocity; RI: Resistive index; S/D: Systolic-to-diastolic ratio; UA: Umbilical artery

\section{Acknowledgements}

None

\section{Authors' contributions}

AAZ contributed to the conception of the study, design of the study, acquisition and analysis of the data, interpretation of data, creation of the final work, study revision, and accuracy or integrity of the submitted manuscript. HAA contributed to the conception of the study, design of the study, acquisition and analysis of the data, interpretation of data, creation of the final work, study revision, and accuracy or integrity of the submitted manuscript. DNY contributed to the conception of the study, design of the study, acquisition and analysis of the data, interpretation of data, creation of the final work, study revision, and accuracy or integrity of the submitted manuscript. All authors have read and approved the manuscript.

\section{Funding}

None

\section{Availability of data and materials}

The datasets used and/or analyzed during the current study are available from the corresponding author on reasonable request.

\section{Ethics approval and consent to participate}

Our study was approved by the ethical and scientific committee, Faculty of Medicine, Menoufia University.

The patients were informed of the examination and gave a verbal informed consent to perform the examination. Written consent is not applicable as they already came seeking antenatal care ultrasonography examination by a written request from their physician

\section{Consent for publication}

All authors gave consent to publish the manuscript.

\section{Competing interests}

The authors declare that they have no competing interests.

Received: 15 October 2019 Accepted: 17 December 2019

Published online: 30 December 2019

\section{References}

1. Alanwar A, El Nour AA, El Mandooh M, Abdelazim IA, Abbas L, Abbas AM, Abdallah A, Nossair WS, Svetlana S (2018) Prognostic accuracy of cerebroplacental ratio for adverse perinatal outcomes in pregnancies complicated with severe pre-eclampsia; a prospective cohort study. Pregnancy Hypertens 14:86-89

2. Rodríguez M, Couve-Pérez C, San Martín S, Martínez F, Lozano C, SepúlvedaMartínez A (2018) Perinatal outcome and placental apoptosis in patients with late-onset pre-eclampsia and abnormal uterine artery Doppler at diagnosis. Ultrasound Obstet Gynecol 51(6):775-782

3. Kreße-Chludek P, Pullankavumkal J, Klöckner N, Henrich W, Verlohren S (2018) Der sFlt-1/PIGF-Quotient als Prädiktor für das Auftreten von Präeklampsie-assoziierten Komplikationen. Ultraschall in Med 39:S1-S47

4. Flatley C, Greer RM, Kumar S (2017) Magnitude of change in fetal cerebroplacental ratio in third trimester and risk of adverse pregnancy outcome. Ultrasound Obstet Gynecol 50(4):514-519

5. Khalil A, Morales-Rosello J, Khan N et al (2017) Is cerebroplacental ratio a marker of impaired fetal growth velocity and adverse pregnancy outcome? Am J Obstet Gynecol 216(6):606.e1-606.10
6. Khalil A, Thilaganathan B (2017) Role of uteroplacental and fetal Doppler in identifying. Fetal growth restriction at term. Best Pract Res Clin Obstet Gynaecol 38:38-47

7. Nassr AA, Abdelmagied AM, Shazly SA (2016) Fetal cerebro-placental ratio and adverse perinatal outcome: systematic review and meta-analysis of the association and diagnostic performance. J Perinat Med 44:249-256

8. Graupner O, Karge A, Flechsenhar S et al (2019) Role of sFlt-1/PIGF ratio and feto-maternal Doppler for the prediction of adverse perinatal outcome in late-onset pre-eclampsia. Arch Gynecol Obstet. https://doi.org/10.1007/ s00404-019-05365-9

9. Ahmed B, Ghaffari Z, Ismail RS, Saleh N (2005) Non-invasive diagnosis of fetal anemia due to maternal red-cell alloimmunization. Saudi Med J 26(2): 256-259

10. Akolekar R, Sarno L, Wright A et al (2015) Fetal middle cerebral artery and umbilical artery pulsatility index: effects of maternal characteristics and medical history. Ultrasound Obstet Gynecol 45(4):402-408

11. Mandic V, Mikovic Z, Filimonović D, Dukić M, Vasiljević M, Bogavac M (2005) Noninvasive diagnosis of fetal anemia in Rh-alloimmunized pregnancies by color Doppler. Med Pregl 58(5-6):275-278

12. Valiño N, Giunta G, Gallo DM et al (2016) Biophysical and biochemical markers at 30-34 weeks' gestation in the prediction of adverse perinatal outcome. Ultrasound Obstet Gynecol 47(2):194-202

13. Bakalis S, Akolekar R, Gallo DM et al (2015) Umbilical and fetal middle cerebral artery Doppler at 30-34 weeks' gestation in the prediction of adverse perinatal outcome. Ultrasound Obstet Gynecol 45(4):409-420

14. Ciobanu A, Wright A, Syngelaki A, Wright D, Akolekar R, NicolaidesKH (2019) Fetal Medicine Foundation reference ranges for umbilical artery and middle cerebral artery pulsatility index and cerebroplacental ratio. Ultrasound Obstet Gynecol 53(4): 465-472

15. Royston P (1995) Calculation of unconditional and conditional reference intervals for fetal size and growth from longitudinal measurements. Stat Med 14(13):1417-1436

16. Altman DG, Chitty LS (1993) Design and analysis of studies to derive charts of fetal size. Ultrasound in Obstetrics and Gynecology 3(6):378-384

17. Wright EM, Royston P (1997) Simplified estimation of age-specific reference intervals for skewed data. Stat Med 16(24):2785-2803

18. Altman DG, Chitty LS (1994) Charts of fetal size: 1. Methodology. Br J Obstet Gynaecol 101(1):29-34

19. Chitty LS, Altman DG, Henderson A, Campbell S (1994) Charts Of fetal size: 2. Head Measurements. Br J Obstet Gynaecol 101(1):35-43

20. Umarwal T, Kumar M (2019) Reference centile chart of fetal cerebroplacental Doppler from 24 to 40 weeks gestation in Indian population. J Obstet Gynaecol India 69(4):339-343

21. Bahlmann F, Fittschen M, Reinhard I, Wellek S, Puhl A (2012) Blood flow velocity waveforms of the umbilical artery in a normal population: reference value from 18 to 42 weeks of gestation. Ultraschall Med 33(7):E80-E87

22. Satomura S (2005) Ultrasonic Doppler method for the inspection of cardiac functions. The Journal of the Acoustical Society of America 29(11):1181-1185

23. Ebrashy A, Azmy O, Ibrahim M, Waly M, Edris A (2005) Middle cerebral/ umbilical artery resistance index ratio as sensitive parameter for fetal wellbeing and neonatal outcome in patients with preeclampsia: case-control study. Croat Med J 46(5):821-825

24. Hernandez-Andrade E, Scheier M, Dezerega V, Carmo A, Nicolaides KH (2004) Fetal middle cerebral artery peak systolic velocity in the investigation of non- immune hydrops. Ultrasound Obstet Gynecol 23(5):442-445

25. Khalil AA, Morales-Rosello J, Morlando M et al (2015) Is fetal cerebroplacental ratio an independent predictor of intrapartum fetal compromise and neonatal unit admission? Am J Obstet Gynecol 213(1):54 e1-54.10

26. Garcia-Simon R, Figueras F, Savchev S, Fabre E, Gratacos E, Oros D (2015) Cervical condition and fetal cerebral Doppler as determinants of adverse perinatal outcome after labor induction for late-onset small-for-gestationalage fetuses. Ultrasound Obstet Gynecol 46(6):713-717

27. Khalil AA, Morales-Rosello J, Elsaddig M et al (2015) The association between fetal Doppler and admission to neonatal unit at term. Am J Obstet Gynecol 213(1):57.e1-57.e7

28. DeVore GR (2015) The importance of the cerebroplacental ratio in the evaluation of fetal well-being in SGA and AGA fetuses. Am J Obstet Gynecol 213(1):5-15

29. Conde-Agudelo A, Villar J, Kennedy SH, Papageorghiou AT (2018) Predictive accuracy of cerebroplacental ratio for adverse perinatal and 
neurodevelopmental outcomes in suspected fetal growth restriction: systematic review and meta-analysis. Ultrasound Obstet Gynecol 52:430-441

30. Vergani P, Roncaglia N, Locatelli A et al (2005) Antenatal predictors of neonatal outcome in fetal growth restriction with absent end- diastolic flow in the umbilical artery. Am J Obstet Gynecol 193(3):1213-1218

31. Bahlmann F, Reinhard I, Krummenauer F, Neubert S, Macchiella D, Wellek S (2002) Blood flow velocity waveforms of the fetal middle cerebral artery in a normal population: reference values from 18 weeks to 42 weeks of gestation. J Perinat Med 30(6):490-501

32. Kurmanavicius J, Streicher A, Wright EM et al (2001) Reference values of fetal peak systolic blood flow velocity in the middle cerebral artery at 19-40 weeks of gestation. Ultrasound Obstet Gynecol 17(1):50-53

33. Dunn L, Sherrell H, Kumar S (2017) Review: systematic review of the utility of the fetal cerebroplacental ratio measured at term for the prediction of adverse perinatal outcome. Placenta 54:68-75

34. Hamill N, Rijhsinghani A, Williamson RA, Grant S (2003) Prenatal diagnosis and management of fetal anemia secondary to a large chorioangioma. Obstet Gynecol 102(5):1185-1188

35. Baschat AA, Gembruch U, Viscardi RM, Gortner L, Harman CR (2002) Antenatal prediction of intraventricular hemorrhage in fetal growth restriction: what is the role of Doppler? Ultrasound Obstet Gynecol 19(4): 334-339

36. Odibo AO, Riddick C, Pare E, Stamilio DM, Macones GA (2005) Cerebroplacental doppler ratio and adverse perinatal outcomes in intrauterine growth restriction: evaluating the impact of using gestational age-specific reference values. J Ultrasound Med 24(9):1223-1228

37. Tarzamni MK, Nezami N, Samani FG, Vahedinia S, Tarzamni M (2009) Doppler waveform indices of fetal middle cerebral artery in normal 20 to 40 weeks pregnancies. Arch Iran Med 12(1):29-34

38. Ebbing C, Rasmussen S, Kiserud T (2007) Middle cerebral artery blood flow velocities and pulsatility index and the cerebroplacental pulsatility ratio: longitudinal reference ranges and terms for serial measurements. Ultrasound Obstet Gynecol 30(3):287-296

39. Detti L, Mari G, Akiyama M et al (2002) Longitudinal assessment of the middle cerebral artery peak systolic velocity in healthy fetuses and in fetuses at risk for anemia. Am J Obstet Gynecol 187(4):937-939

40. Parra-Cordero M, Lees C, Missfelder-Lobos H, Seed P, Harris C (2007) Fetal arterial and venous Doppler pulsatility index and time averaged velocity ranges. Prenat Diagn 27(13):1251-1257

41. Rujiwetpongstorn J, Phupong V (2007) Doppler waveform indices of the Middle Cerebral Artery of normal fetuses in the first half of pregnancy in the Thai population. Arch Gynecol Obstet 276(4):351-354

42. Caradeux J, Martinez-Portilla RJ, Basuki TR, Kiserud T, Figueras F (2018) Risk of fetal death in growth-restricted fetuses with umbilical and/or ductus venosus absent or reversed end-diastolic velocities before 34 weeks of gestation: a systematic review and meta-analysis. Am J Obstet Gynecol 218(2S):S774-82.e21

43. Stampalija T, Arabin B, Wolf H, Bilardo CM, Lees C TRUFFLE investigators (2017) Is middle cerebral artery Doppler related to neonatal and 2-year infant outcome in early fetal growth restriction? Am J Obstet Gynecol 216(5):521.e1-521.13

44. Alfirevic Z, Stampalija T, Medley N (2015) Fetal and umbilical Doppler ultrasound in normal pregnancy. Cochrane Database Syst Rev 15(4): CD001450

45. Chanprapaph P, Wanapirak C, Tongsong T (2000) Umbilical artery doppler waveform indices in normal pregnancies. Thai J Obstet Gynaecol 12:103-107

46. Shahinaj R, Manoku N, Kroi E, Tasha I (2010) The value of the middle cerebral to umbilical artery Doppler ratio in the prediction of neonatal outcome in patient with preeclampsia and gestational hypertension. J Prenat Med 4(2):17-21

47. Baschat AA, Gembruch U (2003) The cerebroplacental Doppler ratio revisited. Ultrasound Obstet Gynecol 21(2):124-127

48. Clerici G, Luzietti R, Cutuli A, Direnzo GC (2002) Cerebral hemodynamics and fetal behavioral states. Ultrasound Obstet Gynecol 19(4):340-343

49. Hsieh YY, Chang CC, Tsai HD, Tsai CH (2001) Longitudinal survey of blood flow at three different locations in the middle cerebral artery in normal fetuses. Ultrasound Obstet Gynecol 17(2):125-128

50. Mari G, Abuhamad AZ, Cosmi E, Segata M, Altaye M, Akiyama M (2005) Middle cerebral artery peak systolic velocity: technique and variability. J Ultrasound Med 24(4):425-430
51. Acharya G, Wilsgaard T, Berntsen GKR, Maltau JM, Kiserud T (2005) Reference ranges for serial measurements of umbilical artery Doppler indices in the second half of pregnancy. Am J Obstet Gynecol 192(3):937-944

52. Napolitano R, Dhami J, Ohuma EO et al (2014) Pregnancy dating by fetal crown-rump length: a systematic review of charts. BJOG 121:556-565

53. Oros D, Ruiz-Martinez S, Staines-Urias E et al (2019) Reference ranges for Doppler indices of umbilical and fetal middle cerebral arteries and cerebroplacental ratio: systematic review. Ultrasound Obstet Gynecol 53(4): 454-464

\section{Publisher's Note}

Springer Nature remains neutral with regard to jurisdictional claims in published maps and institutional affiliations.

\section{Submit your manuscript to a SpringerOpen ${ }^{\circ}$ journal and benefit from:}

- Convenient online submission

- Rigorous peer review

- Open access: articles freely available online

High visibility within the field

- Retaining the copyright to your article

Submit your next manuscript at $\boldsymbol{\nabla}$ springeropen.com 